\title{
Estimation of phylogenetic divergence times in Panagrolaimidae and other nematodes using relaxed molecular clocks calibrated with insect and crustacean fossils
}

\author{
Lorraine M. MCGILl $^{1, *}$, David A. FitzPATRICK ${ }^{1}$, Davide PISAni ${ }^{1,2}$ and Ann M. Burnell ${ }^{1}$ \\ ${ }^{1}$ Department of Biology, National University of Ireland Maynooth, Maynooth, Co. Kildare, Ireland \\ ${ }^{2}$ School of Biological Sciences and School of Earth Sciences, University of Bristol, Woodland Road, \\ Bristol BS8 1UG, UK
}

Received: 23 June 2015; revised: 24 July 2017

Accepted for publication: 24 July 2017; available online: 11 September 2017

\begin{abstract}
Summary - This study presents the use of relaxed molecular clock methods to infer the dates of divergence between Panagrolaimus species. Autocorrelated relaxed tree methods, combined with well characterised fossil calibration dates, yield estimates of nematode divergence dates in accordance with the palaeontological age of fossil ascarid eggs and with the previously estimated date of $18 \mathrm{Ma}$ (range 11.6 to $29.9 \mathrm{Ma}$ ) for the divergence of the Caenorhabditis lineage. Our data indicate that Panagrolaimus davidi from Antarctica separated ca $21.98 \mathrm{Ma}$ from its currently known, most closely related strain. Thus, $P$. davidi may have existed in Antarctica prior to the Last Glacial Maximum, although this seems unlikely as it shares physiological and life history traits with closely related nematodes from temperate climates. These traits may have facilitated colonisation of Antarctica by $P$. davidi after the quaternary glaciation, analogous to the colonisation of Surtsey Island, Iceland, by P. superbus after its volcanic formation. This study demonstrates that autocorrelated relaxed tree methods combined with well characterised fossil calibration dates may be used as a method to estimate the divergence dates within nematodes in order to gain insight into their evolutionary history.
\end{abstract}

Keywords - 18S rDNA SSU, 28S rDNA, Antarctica, Bayesian methods, CIR process, Crustacea, divergence dates, evolutionary history, Insecta, Nematoda evolution, palaeoendemism, Panagrolaimus, Panagrolaimus davidi, Panagrolaimus superbus, Phylobayes, phylogeny, relaxed tree methods, Surtsey Island.

The family Panagrolaimidae comprises predominantly free-living nematodes that have evolved to survive in a wide range of substrates and locations. These freeliving bacteriophage nematodes have been associated with soil, leaf-litter, rotting fruit, rotting wood and other fermenting substrates (Lazarova et al., 2004; Barrière \& Félix, 2006; Stock \& Nadler, 2006; Fonderie et al., 2009; McGill et al., 2015). They have been isolated from diverse habitats such as terrestrial deep subsurface water (Borgonie et al., 2011), deserts (Zhi et al., 2008; Darby et al., 2010) and polar regions (Boström, 1988; Wharton \& Brown, 1989). Many of these locations have unfavourable growth conditions; however, several members of the Panagrolaimidae have adapted to survive in these extreme environments (Shannon et al., 2005; McGill et al., 2015).
Two forms of adaptive response to unfavourable environmental conditions have been described: capacity adaptations, and resistance adaptations (Wharton et al., 2002). Capacity adaptations enable extremophile organisms to grow and reproduce under conditions that would be lethal to most mesophiles, while resistance adaptations allow organisms to survive environmental stress by entering into a dormant state until favourable conditions return. Capacity and resistance adaptations have both been described among members of the Panagrolaimidae. Turbatrix aceti can tolerate extreme $\mathrm{pH}$ environments, maintaining activity from $\mathrm{pH} 1.6-11.0$ and growing between $\mathrm{pH} 3.5-9.0$ (Nicholas, 1984), and Halicephalobus mephisto isolated at a depth of $1.3 \mathrm{~km}$ from hypoxic subsurface fracture water is capable of growing at $41^{\circ} \mathrm{C}$ (Borgonie et al., 2011).

*Corresponding author, e-mail: lorrainemcgill@gmail.com 
Potent resistance adaptation in the form of anhydrobiosis and cryobiosis occurs in several Panagrolaimus species (Aroian et al., 1993; Wharton \& Barclay, 1993; Wharton \& Ferns, 1995; Shannon et al., 2005; McGill et al., 2015). Anhydrobiosis and cryobiosis refer to the reversible ametabolic state that organisms utilise to survive conditions of extreme desiccation (Crowe et al., 1992) and freezing temperatures, respectively (Clegg, 2001). These forms of resistance adaptation are suited to extreme environments, and may aid in dispersal in the case of desiccated anhydrobiotes (Nkem et al., 2006). Panagrolaimus davidi, isolated from Ross Island, Antarctica, is the best characterised example of a nematode that is anhydrobiotic but can also survive freezing when fully hydrated (Wharton \& Ferns, 1995). Phylogenetically, P. davidi is contained within a clade of parthenogenetic, anhydrobiotic and cryotolerant nematodes (McGill et al., 2015). Although P. davidi was isolated in Antarctica, its most closely related strain identified to date is Panagrolaimus sp. PS1579 isolated in San Marino, California (Shannon et al., 2005; Lewis et al., 2009). Outside of this clade there are several other anhydrobiotic and cryobiotic Panagrolaimus species and strains from diverse geographical regions (McGill et al., 2015).

Panagrolaimus superbus was isolated from a gull's nest on Surtsey Island, Iceland (Boström, 1988). Surtsey Island was formed from 1963-1967 by volcanic eruptions (Bladursson \& Ingadóttir, 2007). Therefore, P. superbus cannot have evolved on Surtsey Island; it was transported there following the volcanic origin of the island. A substantial number of Antarctic micro-invertebrates, including nematodes, show a high degree of endemism (Wharton \& Ferns, 1995; Andrássy, 1998; Maslen \& Convey, 2006; Convey \& Stevens, 2007; Convey et al., 2008; Pugh $\&$ Convey, 2008). The close relationship between $P$. davidi and other parthenogenetic, anhydrobiotic and cryotolerant nematodes from temperate regions suggests the possibility that $P$. davidi, like $P$. superbus, may not be endemic to Antarctica (Lewis et al., 2009; McGill et al., 2015) but may have been transported there more recently as an anhydrobiotic propagule. Information on divergence dates among the Panagrolaimidae would greatly increase our understanding of the evolution and dispersal of $P$. davidi.

Estimates of nematode divergence have been hampered both by the paucity of nematode fossils (Poinar \& Boucot, 2006) to calibrate a molecular clock and the substantial heterogeneity of nucleotide substitution rates in different nematode lineages (Blaxter et al., 1998). Despite these problems, molecular clock methods have been used to estimate divergence times amongst nematodes. Various strategies have been utilised: $i$ ) a strict molecular clock, with the molecular clock rate for globin and cytochrome being extrapolated from metazoan phylogenies, predominantly chordate and arthropod (Vanfleteren et al., 1994); ii) the use of a single calibration point for the time of divergence of nematodes from arthropods (Coughlan \& Wolfe, 2002; Stein et al., 2003); and iii) from a taxonomically local clock inferred from internal calibration dates from the neutral mutation rate of selected genes in living populations of Caenorhabditis elegans (Cutter, 2008). The method employed has also been used to approximate the divergence date between $P$. davidi and its closest known relatives (Lewis et al., 2009).

Strict molecular clock methods generally assign a single substitution rate to the entire tree (Zuckerkandl \& Pauling, 1962). However, the realisation that heterogeneity of substitution rates between lineages and rates is common (Welch \& Bromham, 2005) has led to a methodological shift towards relaxed clock methods that does not assume a constant evolutionary rate across the phylogeny (Drummond et al., 2006; Lepage et al., 2007; Lartillot et al., 2009). Since nematodes display great heterogeneity of nucleotide substitution rates between lineages, in this study we employed relaxed molecular clock methods to infer divergence dates within the Panagrolaimidae. We used five palaeontological minimum and maximum date estimates for arthropod lineage splitting events (Benton et al., 2009; Rota-Stabelli et al., 2013) to calibrate the clock. Three relaxed molecular clock methods were tested: the autocorrelated CIR (Lepage et al., 2007) and LogNormal (Thorne et al., 1998) models, and the uncorrelated gamma multipliers (Ugam) model (Drummond $e t$ $a l .$, 2006). The results obtained by these relaxed molecular clock methods were compared with those obtained using the strict molecular clock method. The results of our analyses show that relaxed molecular clock models, when combined with well characterised insect and crustacean fossil calibration dates, give nematode divergence dates that agree with the palaeontological age of fossil ascarid eggs (Poinar \& Boucot, 2006) and the date for the divergence of $C$. elegans and $C$. briggsae as estimated by Cutter (2008) using internal calibration dates derived from neutral substitution rates in living populations of $C$. elegans. These correlations suggest that our estimates for lineage splitting within the Panagrolaimidae are reliable and informative. As far as we are aware, this is the first report on the use of relaxed molecular clock methodology 
combined with fossil-based calibration dates to estimate nematode divergence times.

\section{Materials and methods}

\section{SOURCES AND CULTURING OF NEMATODES}

The sources and geographic origins of Panagrolaimus isolates used in this study are listed in Table 1 . The nematodes were cultured at $20^{\circ} \mathrm{C}$ in the dark on nematode growth medium (NGM) plates supplemented with streptomycin sulphate $\left(30 \mu \mathrm{g} \mathrm{ml}^{-1}\right)$ and containing a lawn of streptomycin-resistant Escherichia coli strain HB101 obtained from the Caenorhabditis Genetics Center (CGC) (http://www.cgc.cbs.umn.edu). Nematodes were harvested from the NGM plates using sterile distilled water as described by McGill et al. (2015).

\section{DNA EXTRACTION AND RDNA SEQUENCING}

Nematode DNA was extracted using a modified version of the DNeasy Blood and Tissue Extraction kit (Qiagen). A 100-200 $\mu$ l packed nematode pellet was ground in $200 \mu \mathrm{l}$ of nematode lysis buffer (20 mM Tris- $\mathrm{HCl}$ pH 7.5, 50 mM EDTA, $200 \mathrm{mM} \mathrm{NaCl}, 0.5 \%$ (w/v) SDS) under liquid nitrogen. The remainder of the extraction protocol followed the manufacturer's instructions for animal tissues, including RNase A digestion.

Primers were designed for the rDNA $18 \mathrm{~S}$ small subunit (SSU) based on alignment of existing panagrolaimid and closely related nematode sequences available in GenBank (http://www.ncbi.nlm.nih.gov/genbank/). The 18S rDNA SSU genes of the Panagrolaimus species ( $P$. superbus, $P$. rigidus sp. AF36, Panagrolaimus sp. PS1579 and Panagrolaimus sp. AS01) were amplified in two overlapping regions as follows: the first half was amplified using 18S_StartF (5'-TAAACACGAAACCGCGTA$\left.3^{\prime}\right)$ and 18S_InternalR (5'-ATCTGATCGCCTTCGATC CT- $\left.3^{\prime}\right)$ primers. The second half was amplified with 18S_InternalF (5'-GTGAAATTCGTGGACCCTTG-3') and 18S_EndR (5'-TACGGCCACCTTGTTACGAC-3') primers. PCR amplicons were cloned into the pJet1.2/ blunt vector (Thermo Fisher Scientific) and transformed into E. coli TOP10 cells (Invitrogen). Plasmids were purified using the Qiaprep Spin Miniprep kit (Qiagen) and sequenced by LGC Genomics (Berlin, Germany). Inserts from a minimum of two plasmids were sequenced in forward and reverse direction and assembled using the CAP3 assembly program (Huang \& Madan, 1999). These new sequences were deposited in GenBank and are listed in Table 2 .

\section{PHYLOGENY RECONSTRUCTION}

The GenBank accession numbers of nematode, arthropod and annelid 18S rDNA SSU and 28S rDNA D3 expansion region of the large ribosomal subunit (LSU) sequences used in this analysis are presented in Table 2. The sequences were aligned using MUSCLE alignment software (Edgar, 2004). The 18S rDNA SSU alignment was optimised by structural alignment with RNAsalsa (Stocsits et al., 2009), using the Saccharomyces cerevisiae rDNA SSU structure as a reference. The 1520 character $18 \mathrm{~S}$ rDNA SSU and 28S rDNA D3 expansions region of LSU sequences were trimmed, concatenated (Fig. S1 in the Supplementary material), and used to infer a Bayesian phylogeny with Phylobayes (version 3.3f) (Lartillot et al., 2009). The annelid and kinorhynch species, Eisenia foetida and Pycnophyes kielensis, were used as outgroups.

Table 1. Source of the Panagrolaimus isolates used in this study.

\begin{tabular}{|c|c|c|c|c|}
\hline Species and strain & Location & Habitat & Source & Reproduction \\
\hline Panagrolaimus davidi & $\begin{array}{l}\text { Ross Island, McMurdo Sound, } \\
\text { Antarctica }\end{array}$ & Moss and algae & Prof. David Wharton & Parthenogenetic \\
\hline Panagrolaimus rigidus sp. AF36 & Fayette County, PA, USA & Soil & $\begin{array}{l}\text { CGC (isolated by } \\
\text { Prof. Andras Fodor) }\end{array}$ & $\begin{array}{l}\text { Male/female } \\
\text { (amphimictic) }\end{array}$ \\
\hline Panagrolaimus superbus & Surtsey Island, Iceland & $\begin{array}{l}\text { Gull's nest in } \\
\text { a lava cavity }\end{array}$ & Prof. Bjorn Sohlenius & $\begin{array}{l}\text { Male/female } \\
\text { (amphimictic) }\end{array}$ \\
\hline Panagrolaimus sp. AS01 & Leixlip, Co. Kildare, Ireland & A roof gutter & Dr Adam Shannon & $\begin{array}{l}\text { Male/female } \\
\text { (amphimictic) }\end{array}$ \\
\hline Panagrolaimus sp. PS1579 & $\begin{array}{l}\text { Huntington Botanical Gardens, } \\
\text { San Marino, CA, USA }\end{array}$ & Soil & $\begin{array}{l}\text { CGC (isolated by } \\
\text { Prof. M.-A. Félix) }\end{array}$ & Parthenogenetic \\
\hline
\end{tabular}


Table 2. GenBank accession numbers for the rDNA sequences used in the molecular clock analyses.

\begin{tabular}{|c|c|c|}
\hline \multirow[t]{2}{*}{ Organism } & \multicolumn{2}{|c|}{ GenBank accession number } \\
\hline & 28S rDNA D3 region & $18 \mathrm{~S}$ rDNA \\
\hline Panagrolaimus superbus & AY878376 & KC522707* \\
\hline Panagrolaimus rigidus sp. AF36 & AY878379 & KC522706* \\
\hline Panagrolaimus davidi & AY878385 & AJ567385 \\
\hline Panagrolaimus sp. PS1579 & AY878383 & KC522714* \\
\hline Panagrolaimus sp. AS01 & FJ717472 & KC522708* \\
\hline Halicephalobus mephisto & GU811759 & GQ918144 \\
\hline Halicephalobus gingivalis & DQ145637 & AF202156 \\
\hline Caenorhabditis elegans & X03680 & X03680 \\
\hline Caenorhabditis briggsae & AY604481 & FJ380929 \\
\hline Nippostrongylus brasiliensis & AM039748 & AJ920356 \\
\hline Trichostrongylus colubriformis & AM039743 & AJ920350 \\
\hline Ascaris suum & FJ418792 & U94367 \\
\hline Pseudoterranova decipiens & AY821763 & U94380 \\
\hline Dorylaimus stagnalis & AY592994 & AY284777 \\
\hline Trichodorus primitivus & AM180729 & AJ439517 \\
\hline Nasonia vitripennis & GQ374784 & GQ410677 \\
\hline Apis mellifera & AY703551 & $\mathrm{AB} 126807$ \\
\hline Chironomus tentans & X99212 & X99212 \\
\hline Aedes albopictus & L22060 & X57172 \\
\hline Musca domestica & AJ551427 & DQ133074 \\
\hline Drosophila melanogaster & M21017, M29800 & M21017, M29800 \\
\hline Daphnia magna & AF532883 & AM490278 \\
\hline Artemia salina & AF169697 & X01723 \\
\hline Pycnophyes kielensis & AY863411 & PKU67997 \\
\hline Eisenia fetida & X79872 & AF212166 \\
\hline
\end{tabular}

* Sequences generated in this study.

Each phylogenetic reconstruction for each nucleotide substitution test was repeated ten times over several random splits and the log likelihood scores averaged. The substitution rate variation was modelled using a Gamma distribution with four discrete categories. Two independent Markov chains were run in parallel and the chains compared for convergence using the tracecomp and bpcomp program with default parameters. When the chains had converged sufficiently (maxdiff $<0.3$ and all effective sizes larger than 50) the chains were stopped, one-fifth of the total number of trees was removed as 'burnin' and the majority-rule posterior consensus tree constructed with the readpb program in Phylobayes.

Cross-validation tests implemented within Phylobayes were used to compare and select the best fitting nucleotide substitution model (Lartillot et al., 2009). The crossvalidation program within Phylobayes splits the dataset into two (unequal) parts: the learning set and the test set. The parameters of the model are trained on the learning set and these parameter values are then used to compute $\log$ likelihood scores of how well the set test is predicted by the model. When comparing two models, a positive value indicates that the test model fits the data better than the reference model (model tested against).

Saturation (i.e., multiple recurrent substitutions at a given site in the sequence alignment) results from homoplasies and it can create convergences between unrelated taxa and inaccurate phylogenetic signal. Therefore, it is important that the molecular clock model anticipates the sequence saturation. In Phylobayes this is achieved using the posterior predictive model checking program ppred using the -sat option. The value of a given summary statistic observed on the true dataset is compared with the null distribution of the summary statistic under the model in a method similar to parametric bootstrapping. Each substitution model was tested for how well the model could anticipate sequence saturation using the Phylobayes ppred program. Where the posterior predictive value returned by 
Table 3. The maximum and minimum date estimates used to calibrate the molecular clock (data from Benton et al., 2009), together with their corresponding node numbers in Figure 2.

\begin{tabular}{lcc}
\hline Node & $\begin{array}{c}\text { Minimum } \\
\text { age (Ma) }\end{array}$ & $\begin{array}{c}\text { Maximum } \\
\text { age (Ma) }\end{array}$ \\
\hline Nematode and Arthropod (Node 23) & 520.5 & 581 \\
Crustaceans and Insects (Node 20) & 510 & 543 \\
Hymenoptera and Diptera (Node 18) & 238.5 & 307.2 \\
Within Diptera (Node 16) & 238.5 & 295.4 \\
Within Hymenoptera (Node 19) & 152 & 243 \\
\hline
\end{tabular}

Phylobayes ppred is similar to the observed homoplasy the model accurately predicts the level of saturation.

\section{Clock analyses}

Divergence times were calculated using Phylobayes (version 3.3f) (Lartillot et al., 2009) using the concatenated 18S/28S rDNA sequence alignment, the optimal tree inferred from the best fitting substitution model (Categories (CAT)-General Time Reversible (GTR)), calibration dates (Table 3), and the outgroup species identities. Two autocorrelated molecular clock models were tested: the CIR process of Lepage et al. (2007) and the LogNormal (Thorne et al., 1998). These were compared with the uncorrelated Ugam molecular clock model (Drummond et al., 2006) and a strict molecular clock. The best-fitting relaxed clock model was selected based on the results of the cross-validation tests and its capacity to anticipate sequence saturation as described above. For non-calibrated nodes, we used a birth-date prior on divergence times and a gamma distributed root prior of $550 \mathrm{Ma}$ (Precambrian, Upper Edicaran) with an SD of 50. We calibrated the clock at five nodes and treated all calibrations as soft-bounds to allow for the possibility that true divergence times may lie outside the specified calibration bounds (Yang \& Rannala, 2006). A value of 2.5\% of the probability to lie outside each calibration interval was allocated (see sensitivity assays). A Markov chain was run for a minimum of 10000 cycles and the posterior mean tree was obtained using the readdiv program implemented with Phylobayes, discarding one-third of the trees as 'burnin'. Five replicate chains were run for each model and priors tested, and ten replicates were used in the final analysis to infer the final molecular clock.

\section{SENSITIVITY ASSAYS}

Bayesian interference as implemented by Phylobayes creates a posterior probability tree using a model of evolution based on prior probability distributions (i.e., to allow for the probability that the true divergence that may lie outside the specified calibration bounds) for each parameter. The following tests were performed to assess the effect of varying the priors on the estimated divergence dates: $i$ ) relaxing the soft-bound by allowing either 2.5 , 10,20 or $50 \%$ of probability mass to be allocated outside the min-max calibration interval; ii) employing a less fit nucleotide substitution model; and iii) altering the SD of the root age. For each test, five replicate chains were ran and only the prior under investigation was changed. Each chain was run for a minimum of 10000 cycles and the posterior mean chromatogram was obtained using the readdiv program implemented with Phylobayes, discarding one-third of the trees as 'burnin'.

\section{Results}

\section{PHYLOGENETIC RELATIONSHIP BETWEEN THE NEMATODES AND ARTHROPODS}

A Bayesian tree was constructed for the Panagrolaimus and other test nematode species along with the arthropod species that were used as palaeontological calibrators (Fig. 1). The CAT-GTR (Fig. 1) and CAT (Fig. S2 in the Supplementary material) substitution models gave similar topologies and fitted the data better than the GTR model (Fig. S3 in the Supplementary material) when compared by cross-validation tests (Table 4) and the estimation of saturation level (Table 5). CAT-GTR was selected as the substitution model for subsequent analysis as it performed better than the CAT model in the cross-validation and saturation tests. The tree topology inferred by the CATGTR model was used as the fixed topology for molecular dating under a variety of clock models. This tree topology has high Bayesian posterior probability support and is in accordance with the current hypothesis of phylogenetic relationship for these taxa. The Panagrolaimus nematodes form a single clade. Halicephalobus mephisto and $H$. gingivalis, also members of the family Panagrolaimidae, form a sister clade to the Panagrolaimus species. All other nematodes are grouped outside the Panagrolaimidae, with Dorylaimia and Enoplia nematodes the most basal in the clade. The arthropods form a single clade. The Diptera (Musca domestica, Drosophilia melanogaster, Chironomus tentans and Aedes albopictus) form a clade, with the Hymenoptera (Nasonia vitripennis and Apis 


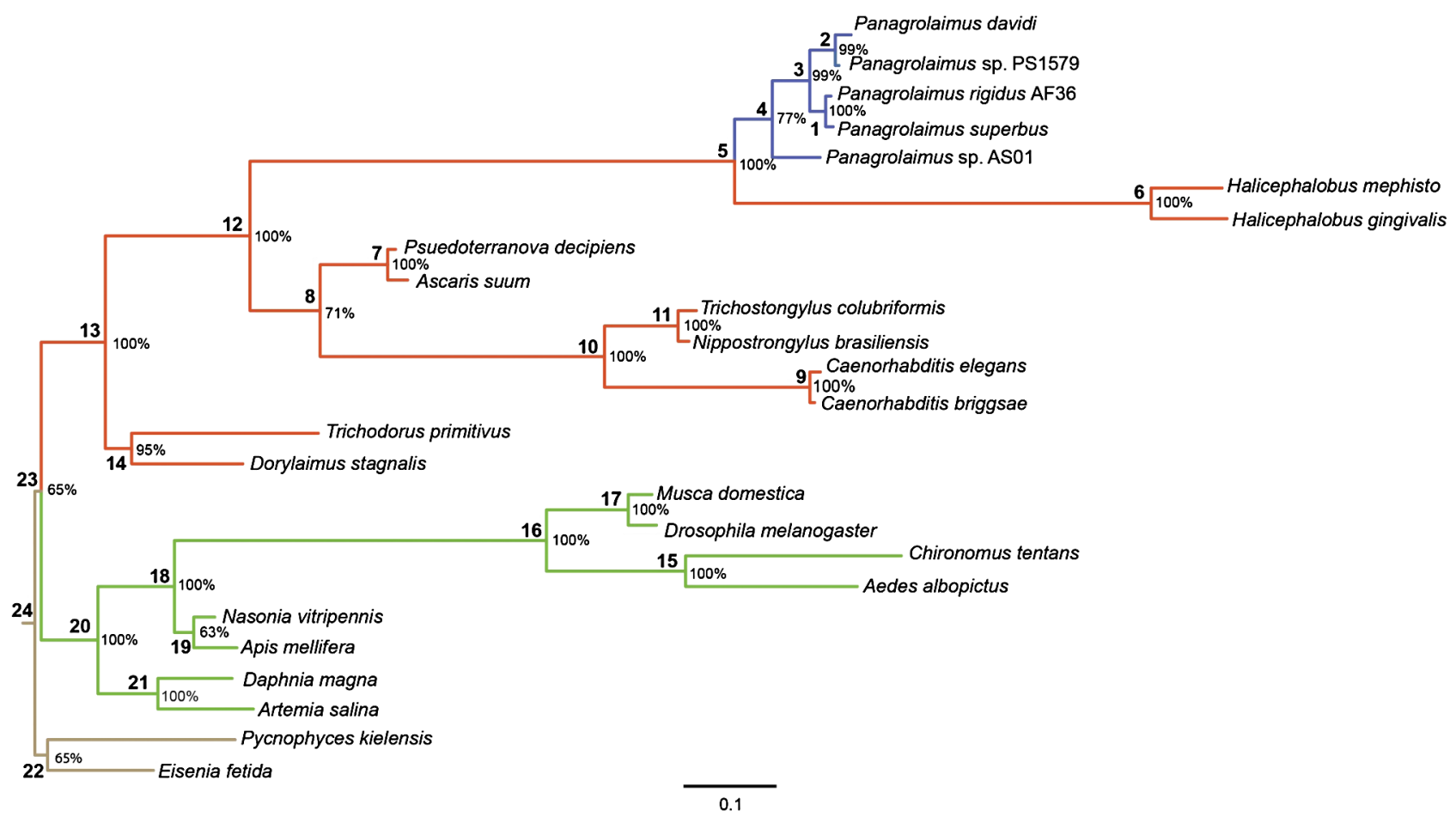

Fig. 1. Hypothesis of phylogenetic relationships among nematodes and arthropod species used for molecular clock analyses. Bayesian inference tree derived from concatenated sequences from the rDNA SSU and 28S rDNA D3 expansion regions of the LSU under the CAT-GTR nucleotide substitution model. The sequences were aligned using MUSCLE (Edgar, 2004) and the 18S rDNA alignment was optimised with RNAsalsa (Stocsits et al., 2009). Branch supports and the node numbers are shown in bold. Panagrolaimus sp. are collared, other nematodes are indicated in red, arthropod calibrator species are indicated in green and outgroups are in brown.

Table 4. Cross-validation of substitution models \pm SD.

\begin{tabular}{lccc}
\hline Reference* & GTR-CAT & CAT & GTR \\
\hline GTR-CAT & - & $-2.636 \pm 6.47421$ & $-7.197 \pm 5.77984$ \\
CAT & $2.636 \pm 6.47421$ & - & $-4.561 \pm 9.11368$ \\
GTR & $7.197 \pm 5.77984$ & $4.561 \pm 9.11368$ & - \\
\hline
\end{tabular}

* A positive value for the test model against the reference models indicates that the test model fits the data better.

Table 5. Substitution model prediction of sequence saturation \pm SD.

\begin{tabular}{lcr}
\hline Model & Observed homoplasy & Posterior predictive \\
\hline GTR-CAT & $3.15361 \pm 0.251034$ & $3.12606 \pm 0.260003$ \\
CAT & $3.06436 \pm 0.24575$ & $3.05596 \pm 0.262086$ \\
GTR & $1.8788 \pm 0.0708481$ & $1.8116 \pm 0.095836$ \\
\hline
\end{tabular}

mellifera) forming a separate group. The crustaceans (Daphnia magna and Artemia salina) form a distinct clade constituting the sister group of the insects.

\section{MOLECULAR CLOCK ANALYSIS}

Having selected CAT-GTR as the best-fitting nucleotide substitution model (Tables 4, 5) we compared divergence dates under four different molecular clock models: the autocorrelated LogNormal and CIR models, the uncorrelated gamma model, and the strict molecular clock model. Cross-validation tests of the molecular clock models tested under a CAT-GTR fixed tree topology found that there was no clear best-fit model between CIR, LogNormal and Ugam (Table 6). The strict molecular clock was found to fit the data considerably less than the CIR, Log- 
Table 6. Cross-validation of molecular clock models \pm SD.

\begin{tabular}{lcccc}
\hline Reference* $^{*}$ & CIR & LN & Ugam & Strict \\
\hline CIR & - & $1.242 \pm 2.0816$ & $2.582 \pm 3.21491$ & $-70.878 \pm 11.417$ \\
LN & $-1.242 \pm 2.0816$ & - & $1.34 \pm 1.48416$ & $-72.12 \pm 12.852$ \\
Ugam & $-2.582 \pm 3.21491$ & $-1.34 \pm 1.48416$ & - & $-73.46 \pm 13.0805$ \\
Strict & $70.878 \pm 11.417$ & $72.12 \pm 12.852$ & $73.46 \pm 13.0805$ & - \\
\hline
\end{tabular}

* A positive value for the test model against the reference models indicates that the test model fits the data better.

Table 7. Molecular clock model prediction of sequence saturation \pm SD.

\begin{tabular}{lcc}
\hline Model & Observed homoplasy & Posterior predictive \\
\hline CIR + GTR-CAT & $2.67699 \pm 0.175591$ & $2.66249 \pm 0.187497$ \\
CIR + GTR & $1.848 \pm 0.0709461$ & $1.78675 \pm 0.0871034$ \\
CIR + CAT & $2.48757 \pm 0.150912$ & $2.48319 \pm 0.160678$ \\
LN + GTR-CAT & $2.93967 \pm 0.212665$ & $2.92201 \pm 0.221946$ \\
Ugam + GTR-CAT & $3.78092 \pm 1.01431$ & $3.77079 \pm 1.04156$ \\
Strict + GTR-CAT & $2.80579 \pm 0.195787$ & $2.76971 \pm 0.202151$ \\
\hline
\end{tabular}

Normal and Ugam models (Table 6). Each model was also tested for its ability to predict sequence saturation when run under a CAT-GTR fixed topology (Table 7). All models predicted similar levels of sequence saturation to those observed in the sequence data. The uncorrelated Ugam model predicted higher saturation that the other models, but, with a comparatively high SD for these values, it was not considered to be significantly different to the other models with low SD values.

The optimal dates at each node for the CIR, LogNormal and Ugam model were compared and plotted (Fig. 2A, B). The optimal dates between each model for each node were highly correlated (Table S1 in the Supplementary material) with a highly significant $P$-value of $<0.0001$. The dates between the CIR and LogNormal autocorrelated models were similar (Spearman $r=0.9757, R^{2}=$ 0.9682) (Fig. 2A). The Ugam and CIR results were also similar (Spearman $r=0.9704, R^{2}=0.9075$ ), with the largest difference between the models at node 14 (Dorylaimia and Enoplia) 21 (crustaceans) and 22 (Annelida and Kinorhyncha) (Fig. 2B). For nodes 14, 21 and 22, the Ugam model predicts a wide range of minimum and maximum divergence dates (Fig. S4B in the Supplementary material). The CIR optimal date lies within the dates of the Ugam for nodes 14, 21 and 22, but with a lower optimal divergence date. The optimal divergence dates when compared to the strict molecular clock (Fig. 2C) were correlated (Spearman $r=0.947$,
$\left.R^{2}=0.9030\right)$; however, when comparing the maximum and minimum divergence dates of each model the strict model differs (Fig. S4C). The strict model has a narrow range between its minimum and maximum dates. For many of the nodes the maximum dates (Table S1) are lower than the optimal dates of the other models, so the strict model may underestimate the divergence dates.

Since the strict model was predicted to fit to the data least by cross-validation it was not considered further. The Ugam model was also discarded because the range between the minimum and maximum divergence dates that it generated was wide with differences of up to 457 Ma (Fig. S4B). The correlated CIR and LogNormal autocorrelated models gave similar optimal, minimum and maximum dates and from cross-validation and saturation tests either model would be suitable for further analysis (Fig. S4A). The CIR model was selected for the final molecular clock (Fig. 3; Table 8) as globally the range between the minimum and maximum dates was narrower with this model than with the LogNormal model.

The estimated molecular divergence times for four of the five calibration nodes obtained using the autocorrelated CIR model were similar to the fossil calibration dates (Table 3), with the optimal divergence dates lying within the range of the minimum and maximum dates proposed by Benton et al. (2009). The only date that differed was the estimated date of 321.2 Ma (306.5-342.6 Ma) for the divergence between the Hymenoptera and the Diptera. This is older than the date used for calibrating the tree (238.5-307.2 Ma). However, recent phylogenies present evidence that the divergence of the Hymenoptera from the other holometabolous insects (including the Diptera) is much older than 238.5-307.2 Ma. Misof et al. (2014) estimated the divergence date between the Hymenoptera and the Diptera at 344.7 Ma (317.8-372.4 Ma) - the optimal divergence date that we obtained for the divergence between the Hymenoptera and the Diptera under the CIR model lies within this range. 

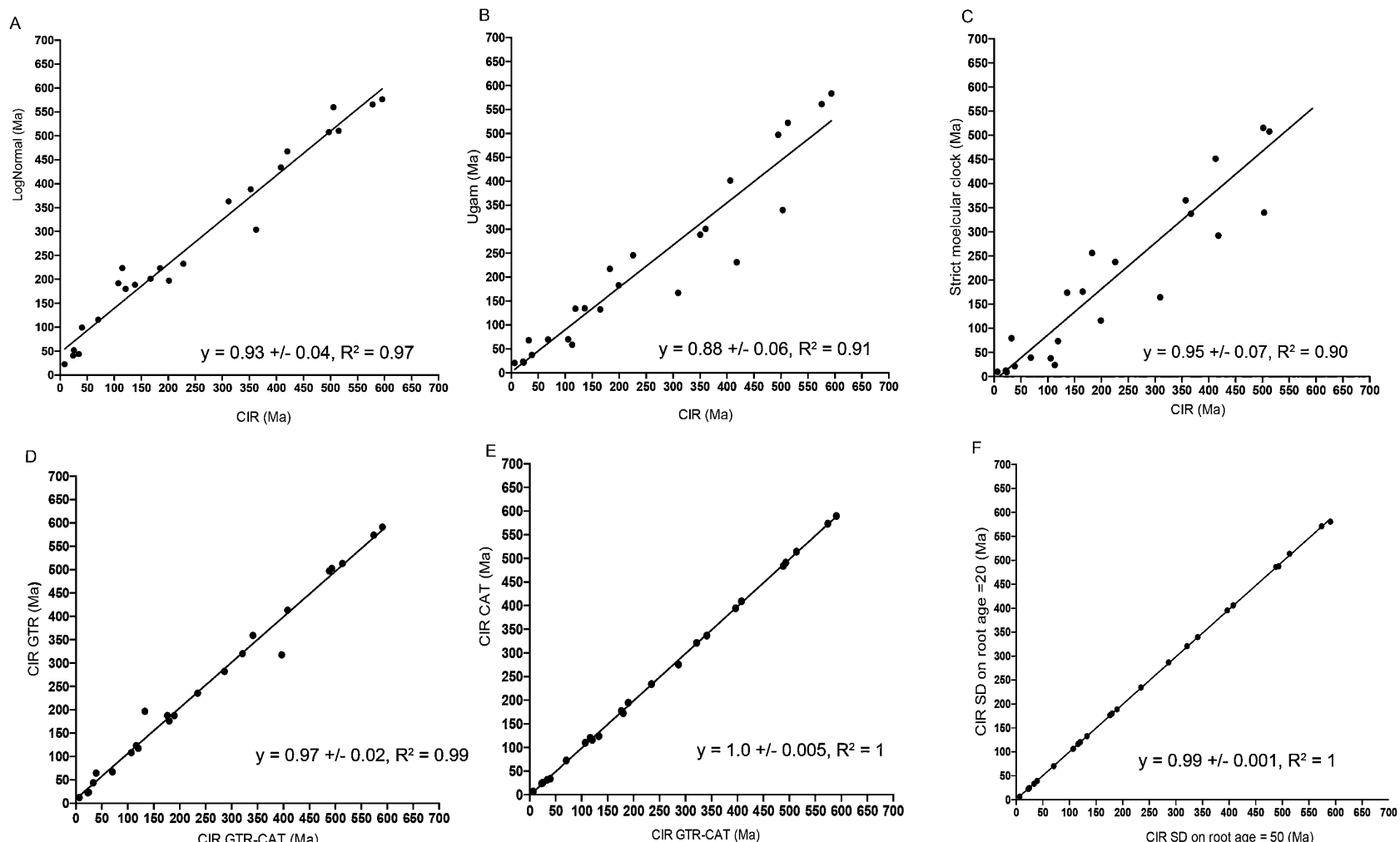

Fig. 2. Sensitivity experiments showing the effect of different models and parameters. Divergence dates were assessed after varying different priors, and dates plotted ( $y$-axis) against the dates obtained under the best-fitting model and priors (CIR + CAT-GTR models, with default soft-bound and using calibrator dates) to investigate the properties (slope and $R^{2}$ ) of the regression line interpolating the two estimates. A: CIR model compared to the LogNormal model; B: CIR model compared to the Ugam model; C: CIR model compared to the strict molecular clock; D: CIR model with the CAT-GTR nucleotide substitution model compared to the CIR model with the GTR nucleotide substitution model; E: CIR model with the CAT-GTR nucleotide substitution model compared to the CIR model with the CAT nucleotide substitution model; F: CIR with a root-age SD $=50$ Ma compared to CIR with a root-age SD $=20$. Each dot represents a node as indicated in Figure 1.

\section{SENSITIVITY ASSAYS}

\section{Relaxing the soft-bounds}

A soft-bound prior probability distribution may be applied to the calibration dates to allow for the probability that the true divergence times may lie outside the specified calibration bounds (Yang \& Rannala, 2006). The effect of varying the soft-bound prior on the divergence dates for each node was tested for 10, 20 and 50\% (Table S2 in the Supplementary material). Changing the soft-bound prior does not affect the majority of the nodes but the divergence dates for nodes 15, 16, 17 become younger and the divergence dates for nodes 18 and 21 become older as the soft-bounds are relaxed. Altering the soft-bound has the largest impact on nodes that have been calibrated rather than nodes near the root or within the nematodes.
As we do not have any calibration points within the nematode section of the tree, the strictest setting of a default value of $2.5 \%$ was maintained as the soft-bound prior in the final molecular clock (Fig. 3) and for all subsequent analyses.

\section{Employing a less fit nucleotide substitution model}

Cross-validation and saturation tests found the CATGTR nucleotide substitution model to fit the data best. Saturation test showed that the CIR model combined with either CAT-GTR or CAT nucleotide substitution models predicted similar levels of saturation and the predicted levels of saturation were similar to those observed in the sequence data (Table 7). The CIR model, when combined with the GTR nucleotide substitution model, predicted 


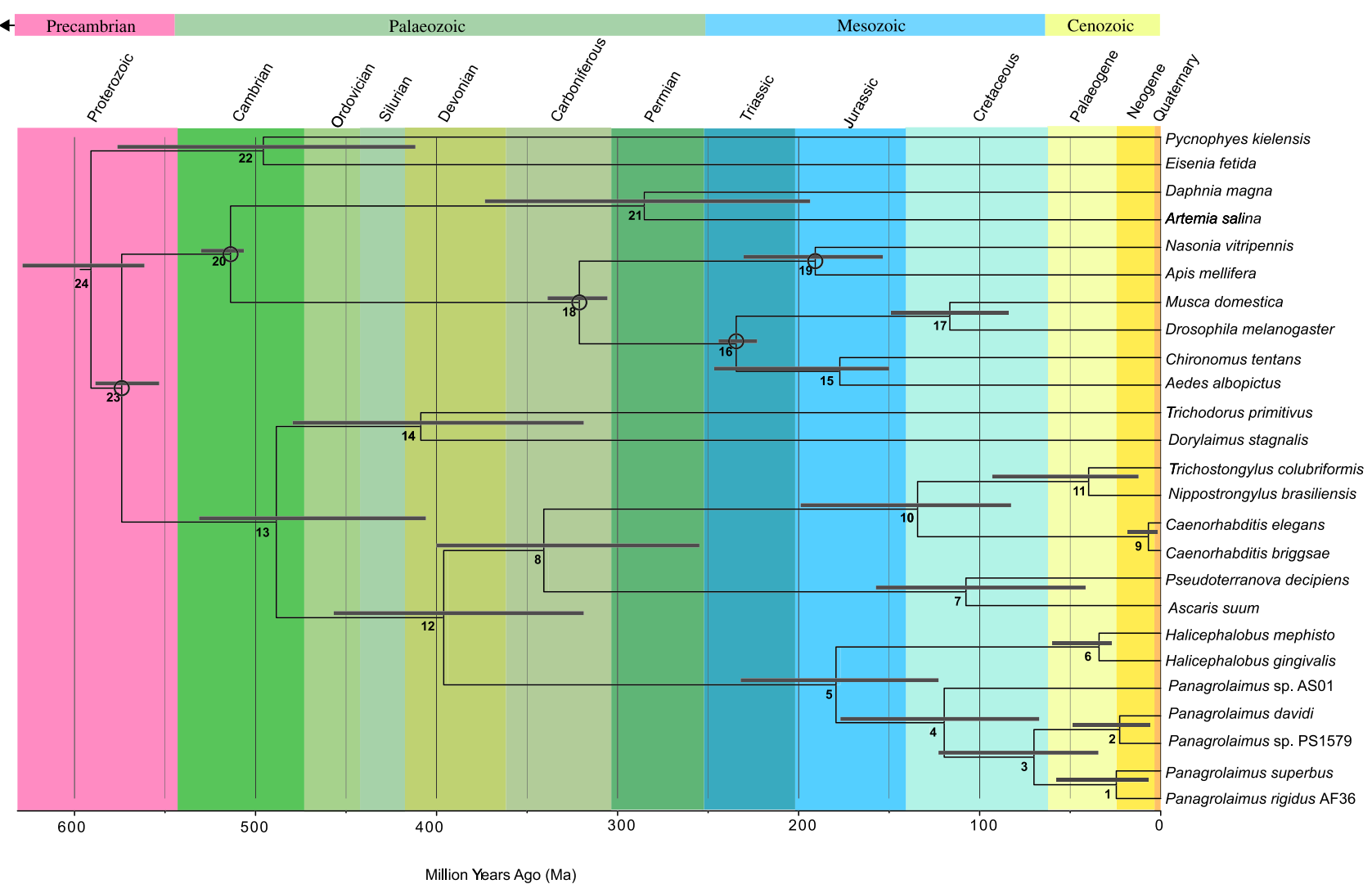

Fig. 3. Chronogram obtained for selected nematode taxa using the autocorrelated CIR model (Lepage et al., 2007) applied to rDNA SSU and 28S rDNA D3 expansion regions of the LSU. The 95\% credibility intervals for the age expansion estimates (grey bars) are shown at each node. Fossil calibration dates for nodes 16, 18, 19, 20 and 23 (Table 3) were obtained from Benton et al. (2009) and are indicated by open circles.

less saturation than observed and detected less saturation than all other model combinations.

There was no effect on the optimal, minimum and maximum estimated divergences when comparing either nucleotide substitution model with the CIR model for the majority of nodes (Fig. 2D, E; Table S3 in the Supplementary material). Under the CIR + GTR, node 10 (C. elegans/C. briggsae and T. colubriformis/N. brasiliensis) and node 12 (Panagrolaimidae and other nematodes) estimated older divergence dates than the CIR + CATGTR or CIR + CAT combinations and, as nematode divergence dates are the subject of this study and the crossvalidation and saturation data found GTR to be the least fit model, the GTR substitution model was not used in subsequent analyses. When combined with CIR, the CAT-GTR and CAT models give near identical divergence dates. Since the CAT-GTR model was found to fit better following saturation and cross-validation tests, it was used for all subsequent analysis in combination with the CIR molecular clock model.

\section{Altering the SD on the root age prior}

Lartillot et al. (2009) strongly advise the explicit declaration of a prior value for the root when calculating molecular divergence times. We specified a prior root age of $550 \mathrm{Ma}$ (Precambrian, Upper Edicaran (Cohen et al., 2013; updated), and investigated the effect of changing the $\mathrm{SD}$ of the root age prior probability value from 50-20 Ma. Five replicate chains were ran and the mean divergence times were calculated and compared to a SD of the root age prior of $50 \mathrm{Ma}$ (Table S4 in the Supplementary material). Changing the SD did not affect the divergence time for any node $\left(R^{2}=0.999, P\right.$-value $\left.=0.0001\right)$ (Fig. 2F). A prior age of $550 \mathrm{Ma}$ with an SD of 50 was used in the final CIR CAT-GTR analysis (Fig. 3). 
Table 8. The optimal, minimum and maximum divergence dates estimated for each node by the CIR molecular clock model + CAT-GTR nucleotide substitution model.

\begin{tabular}{lccc}
\hline & CIR optimal & CIR min & CIR max \\
\hline Node 1 & $24.76 \pm 0.13$ & $7.28 \pm 0.06$ & $56.65 \pm 0.68$ \\
Node 2 & $22.94 \pm 0.1$ & $7.81 \pm 0.1$ & $49.96 \pm 0.2$ \\
Node 3 & $70.51 \pm 0.33$ & $31.97 \pm 0.21$ & $122.17 \pm 0.94$ \\
Node 4 & $120.37 \pm 0.38$ & $68.72 \pm 0.26$ & $178.64 \pm 0.73$ \\
Node 5 & $179.99 \pm 0.33$ & $123.52 \pm 0.91$ & $241.31 \pm 0.47$ \\
Node 6 & $33.52 \pm 0.08$ & $17 \pm 0.09$ & $62.94 \pm 0.23$ \\
Node 7 & $106.93 \pm 0.26$ & $50.58 \pm 0.32$ & $163.49 \pm 0.57$ \\
Node 8 & $341.16 \pm 0.44$ & $269.22 \pm 1.17$ & $400.77 \pm 0.65$ \\
Node 9 & $6.62 \pm 0.03$ & $2.18 \pm 0.01$ & $17.52 \pm 0.24$ \\
Node 10 & $133.09 \pm 0.4$ & $78.34 \pm 0.54$ & $198.48 \pm 0.95$ \\
Node 11 & $39.34 \pm 0.22$ & $12.51 \pm 0.11$ & $85.11 \pm 0.84$ \\
Node 12 & $396.66 \pm 0.48$ & $322.37 \pm 0.92$ & $456.92 \pm 0.72$ \\
Node 13 & $488.25 \pm 0.38$ & $430.82 \pm 1.2$ & $530.55 \pm 0.43$ \\
Node 14 & $407.92 \pm 0.28$ & $319.79 \pm 0.82$ & $473.66 \pm 0.42$ \\
Node 15 & $176.4 \pm 0.22$ & $147.25 \pm 0.54$ & $201.2 \pm 0.33$ \\
Node 16 & $234.54 \pm 0.02$ & $221.56 \pm 0.11$ & $242.4 \pm 0.09$ \\
Node 17 & $116.35 \pm 0.22$ & $77.91 \pm 0.71$ & $148.98 \pm 0.41$ \\
Node 18 & $321.16 \pm 0.07$ & $306.45 \pm 0.05$ & $342.57 \pm 0.33$ \\
Node 19 & $189.65 \pm 0.19$ & $153.47 \pm 0.2$ & $232.72 \pm 0.36$ \\
Node 20 & $513.67 \pm 0.02$ & $507.98 \pm 0.02$ & $525.62 \pm 0.12$ \\
Node 21 & $286.34 \pm 0.61$ & $191.57 \pm 0.83$ & $369.6 \pm 0.46$ \\
Node 22 & $493.13 \pm 0.59$ & $411.15 \pm 1.48$ & $577.9 \pm 1.11$ \\
Node 23 & $573.95 \pm 0.04$ & $555.4 \pm 0.12$ & $584.03 \pm 0.05$ \\
Node 24 & $590.58 \pm 0.22$ & $564.84 \pm 0.13$ & $627.85 \pm 0.55$ \\
\hline
\end{tabular}

\section{Discussion}

Nematoda are soft-bodied and as most are only millimetres in length they fossilise poorly. There are two main sources of nematode fossils: in amber or in coprolites of subfossils. Since the nematode fossil record is poor and palaeontological evidence of divergence is lacking for the vast majority of nematodes, including the Panagrolaimidae, other methods to calculate divergence times are required. Our data demonstrate that phylogenetic relaxed molecular clock methods, combined with well-established fossil dates of arthropods and crustaceans, provide an accurate method to estimate nematode divergence dates and gain insight into their evolutionary history.

\section{SELECTION OF THE MOST APPROPRIATE NUCLEOTIDE SUBSTITUTION MODEL AND MOLECULAR CLOCK MODEL FOR THE NEMATODE AND ARTHROPOD LINEAGES IN THIS DATASET}

The rate of nucleotide substitution during evolutionary time varies between nucleotide character states at a given site and can also vary across the nucleotide sites in a DNA sequence. For example, sites that are more constrained by natural selection show fewer substitutions than sites that are less constrained. Failure to take into account this rate heterogeneity among sites can lead to biased estimations of branch lengths, with corresponding impacts on estimates of evolutionary timescales (Jia et al., 2014). In cross-validation and nucleotide saturation tests the CATGTR substitution model was found to fit best the observed substitution rates across the nucleotide sites in our rDNA alignment. Under the CAT (Categories) model, each site in the alignment is potentially heterogeneous with respect to the substitution process, with the total number of classes being a free variable that reflects the substitutional complexity of the underlying data set (Lartillot \& Philippe, 2004). The general time-reversible (GTR) model includes parameters that allow unequal frequencies for the four nucleotides and a distinct rate for each of the six possible pairwise nucleotide substitutions (Jia et al., 2014). Combining the GTR model for nucleotide substitution at a given nucleotide site with the CAT across sites substitution rate model has frequently been found to fit both nucleotide and amino acid alignment data better than either the GTR or CAT model alone (Lartillot et al., 2009).

The divergence time estimates obtained using four molecular clock evolutionary models were compared in a series of cross-validation and sensitivity tests to determine which molecular clock model had best described our nematode and arthropod rDNA alignment. Three relaxed molecular clock methods were tested; $i$ ) the autocorrelated CIR (Lepage et al., 2007) and LogNormal (Thorne et al., 1998) models; ii) the uncorrelated gamma multipliers (Ugam) model (Drummond et al., 2006); and iii) the strict molecular clock molecular clock model. A strict molecular clock model considers that nucleotide substitutions occur at a constant rate through time among all lineages in a phylogeny. Relaxed molecular clock models allow the substitution rate to vary among lineages, and autocorrelated relaxed clock models assume that neighbouring branches in a phylogeny share similar rates of evolution and that the rate of evolutionary change along a branch depends on the time duration of the branch (Lepage et al., 2007). In this way, the substitution rate under the relaxed clock model can be regarded as a trait that evolves through time, perhaps in correlation with life-history characteristics (Ho \& Duchene, 2014). Cross-validation assays indicated that for our dataset the CIR (Lepage et al., 2007) and LogNormal (Thorne et al., 1998) autocorrelated molecular clock models outperformed the uncorre- 
lated gamma multipliers model (Drummond et al., 2006) and the strict molecular clock model. The divergence date estimates obtained under the CIR model were selected for the final molecular time tree (Fig. 3) because the ranges between the minimum and maximum divergence dates at individual nodes were narrower with this model than with the LogNormal model. Sensitivity assays showed that the divergence dates obtained using the CIR clock model remained robust when tested for changes to the soft-bound probabilities of the calibration dates when using an inferior nucleotide substitution model or when the standard deviation of the root age was changed. Having tested a representative selection of the available molecular models and approaches for estimating variations in nucleotide substitution rates among lineages in phylogenetic trees, we consider that the estimated divergence dates we present for the nematode lineages in this study are robust and reliable.

\section{SUPPORT FOR MOLECULAR DATE ESTIMATES FROM FOSSIL ASCARID EGGS}

Validation of our molecular clock divergence estimates are found in nematode eggs identified as members of the family Ascarididae that were isolated in dinosaur coprolites from the Bernissart Iguanodon beds in Belgium (Poinar \& Boucot, 2006). This bone bed is dated between the upper Barremian and lowermost Aptian age of the Cretaceous period 124-127.24 Ma (Schnyder et al., 2009). According to our molecular clock analyses, the estimated divergence time for Ascaris (Ascaridida: Ascarididae) and Pseudoterranova (Ascaridida: Anisakidae) under the CIR model is (50.58-163.49 Ma), with an optimal date of $106.9 \mathrm{Ma}$. This is in good agreement with the data for the Benissart nematode fossils, considering that palaeontological dates always post-date the cladogenetic events identified by molecular data.

\section{DiVERGENCE TIME ESTIMATES FOR C. ELEGANS AND C. BRIGGSAE}

The divergence time of $C$. elegans and $C$. briggsae is of much scientific interest. Previously, the divergence time of $C$. elegans and C. briggsae was estimated to be 80-110 Ma based on the divergence date between nematodes and arthropods of $c a 800-1000$ Ma used to calibrate the clock (Stein et al., 2003). However, it is now clear that the 800-1000 Ma split between arthropods and nematodes is inaccurate (Erwin et al., 2011; RotaStabelli et al., 2013). The split between arthropods and nematodes occurred more recently at 520-581 Ma (Benton et al., 2009). Cutter (2008) obtained a divergence date of $18 \mathrm{Ma}$ (range 11.6-29.9 Ma) for these two Caenorhabditis species. This result was obtained analytically, assuming: i) a fixed mutation rate, estimated from $C$. elegans data; ii) that each year corresponds to six generations in $C$. elegans and C. briggsae; and iii) that equal rates of substitution had occurred in the seven Caenorhabditis species considered. Our results agree with those of Cutter (2008) in supporting a recent divergence time between $C$. elegans and C. briggsae (6.6 Ma, range 2.2-17.5 Ma). A large number of inferences have been drawn with reference to rates of genomic evolution in Nematoda and in animals more broadly (e.g., Lynch, 2007). Many were based on divergence estimates of $c a 100$ Ma between $C$. elegans and C. briggsae. Based on our results and the results of Cutter (2008) it is clear that many of these conclusions need to be reassessed using a more recent divergence date estimate.

\section{Molecular DATE ESTIMATES LINEAGE SPLITTING EVENTS IN PANAGROLAIMIDAE}

Within the order Rhabditida our estimates place the divergence of Panagrolaimidae within the Devonian at 406.18 Ma (322.37-456.92 Ma). The estimated divergence time of Panagrolaimus and Halicephalobus (both members of the superfamily Panagrolaimidae) was in the Jurassic at 178 Ma (123.5-241.3). By the Cretaceous an anhydrobiotic phenotype had evolved in the ancestor of the lineage leading to the davidi, superbus and Panagrolaimus sp. AS01 clades. Halicephalobus mephisto was originally recovered from a borehole of palaeowater, ${ }^{14} \mathrm{C}$ dating estimating the age of this borehole palaeowater at 4500-6000 BP (Borgonie et al., 2011). Our molecular clock analyses estimates the date of divergence between H. mephisto and H. gingivalis at $33.5 \mathrm{Ma}(17.0-62.9 \mathrm{Ma})$, indicating that these two lineages are considerably older than the date of the origin of the borehole palaeowater where $H$. mephisto was originally isolated.

Our data predict that the optimal mean divergence times for the Antarctic P. davidi and the Californian Panagrolaimus sp. PS1579 is $21.98 \mathrm{Ma}$ (Aquitanian, Miocene). Prior to this lineage-splitting event, the common ancestor of the members of the davidi clade already possessed a robust freezing-tolerant phenotype along with the capacity to inhibit the growth and recrystallisation of ice (McGill et al., 2015). Lewis et al. (2009) inferred divergence estimates of 14000-140000 years between $P$. davidi and Panagrolaimus sp. PS1579, a date that is sig- 
nificantly younger than the divergence dates estimated in our analyses. The divergence dates estimated by Lewis et al. (2009) are based on extrapolation from the rate of silent mutation in C. elegans and an assumption of either ten or one nematode generations per year in these Panagrolaimus species. It is difficult to estimate the number of generations per year for a genus that can survive for more than 8 years in an anhydrobiotic state (Aroian et $a l ., 1993)$. If $P$. davidi and/or its sister species have experienced cumulative periods of anhydrobiosis during their evolutionary history, their divergence time is likely to be older than that proposed by Lewis et al. (2009).

\section{Is P. DAVIDI PALAEOENDEMIC TO THE ANTARCTIC?}

In the early Eocene Epoch (ca $55 \mathrm{Ma}$ ) Australia began to separate from Antarctica and drift northwards, allowing the Antarctic Circumpolar Current to develop and resulting in the thermal isolation of the Antarctic continent (Kennett, 1977). During the Oligocene (38-22 Ma) glacial conditions became established throughout Antarctica. High cooling rates occurred in Antarctica during the middle Miocene ( $\mathrm{ca} 14 \mathrm{Ma}$ ), a step often referred to as the Miocene climate transition (Flower \& Kennett, 1993). Our data indicate that $P$. davidi separated from Panagrolaimus sp. PS1579 22.9 Ma (7.8-50 Ma) - a period when the Antarctic cryosphere was expanding rapidly. A similar divergence date was estimated for the anhydrobiotic and freezing-tolerant nematodes $P$. superbus (Surtsey, Iceland) and $P$. rigidus (Pennsylvania, USA).

The reproductive and ecophysiological characters required for survival in Antarctic environments are generally consistent with the predictions of adversity (A) or stress (S) selection (Greenslade, 1983; Convey, 2000, 2009). Such A/S selected traits, viz., long life span, parthenogenesis, low reproductive rates, low temperature thresholds for activity, and tolerance of extreme cold during low energy-cost dormancy (Greenslade, 1983), are clearly seen in the Antarctic nematode Scottnema lindsayae. Scottnema lindsayae is the sole member of a monotypic genus that is anhydrobiotic (Treonis et al., 2000) and freezing-tolerant (Wharton \& Raymond, 2015), and is abundant and widespread in coastal regions and some nunataks in continental Antarctica. In the laboratory its optimal growth temperature is $10^{\circ} \mathrm{C}$ (Caldwell, 1981), its reproductive cycle is 218 days and its fecundity declines if cultured at a higher temperature (Overhoff et al., 1993). By contrast, $P$. davidi possesses $r$-selected traits: high fecundity, rapid growth rates, and a short life cycle (Brown et al., 2004; Stocsits et al., 2009) - traits that are typical of many temperate nematodes with high colonising ability (Bongers, 1990). The optimal growth temperature of $P$. davidi is $c a 25^{\circ} \mathrm{C}$ and its life cycle at this temperature is ca 10 days. At a lower temperature of $10^{\circ} \mathrm{C}$ its life cycle increases to $\mathrm{ca} 36$ days, with a greatly reduced fecundity (Brown et al., 2004; Stocsits et al., 2009).

While many Antarctic invertebrates (including Scottnema) are likely to be palaeoendemic to Antarctica (Convey \& Stevens, 2007; Pugh \& Convey, 2008), the great majority of Antarctica biota (particularly arthropods and bryophytes) are most probably recent colonists that became established in Antarctica after the end of the quaternary glaciation $c a$ 10000-15000 years ago (Convey, 2009). The time since the last Pleistocene glaciation is relatively short in evolutionary terms for new capacity and resistance adaptations to arise in Antarctic invertebrates, particularly allowing for their extended life cycles. Thus, Convey (2009) hypothesises that Antarctic colonisers need to have prior possession of the behavioural, ecophysiological and biochemical phenotypes necessary for their survival in Antarctica. Our data indicate that P. davidi separated from Panagrolaimus sp. PS1579 ca $22.9 \mathrm{Ma}$, and thus P. davidi may have existed in Antarctica prior to the Last Glacial Maximum. However, we feel that this is unlikely and hypothesise that $P$. davidi may have been transported in an anhydrobiotic state to Antarctica at a more recent date. We believe this because the physiological and life history traits of $P$. davidi show no evidence of an evolved response to polar conditions that differs from closely related nematodes from temperate climates. All members of the $P$. davidi clade are anhydrobiotic, freezing-tolerant, parthenogenetic, and have $r$ selected reproduction. This combination of reproductive and $\mathrm{A} / \mathrm{S}$ selected resistance phenotypes is likely to have contributed to the wide geographic dispersal of the members of the clade and facilitated the colonisation of Antarctica by $P$. davidi after the end of the quaternary glaciation in a manner analogous to the recent colonisation of Surtsey Island by $P$. superbus.

\section{Conclusion}

The lack of nematode fossils has made the estimation of divergence dates of nematodes difficult. This study demonstrates that relaxed molecular clock methods, in combination with known insect and crustacean fossil divergence dates, can provide accurate and reliable divergence date estimates for nematodes. Using molecular phylogenetic methods, we have estimated the divergence 
dates for anhydrobiotic and freezing tolerant lineages of Panagrolaimus nematodes, thereby providing an insight into their evolutionary history. On the basis of these divergence dates, combined with physiological traits, we hypothesise that the nematode $P$. davidi is a recent coloniser of the Antarctic. This analysis was completed using $c a$ 1500 characters from two ribosomal gene sequences. With the ongoing generation of large-scale nematode sequence datasets, relaxed molecular methods are likely to be more widely used to investigate and robustly confirm nematode divergence dates.

\section{Acknowledgement}

This project was funded by Science Foundation Ireland (Projects 08/RFP/EOB166 and 09/RFP/EOB2506).

\section{References}

Andrássy, I. (1998). Nematodes of the sixth continent. Journal of Nematode Morphology and Systematics 1, 107-186.

Aroian, R.V., Carta, L., Kaloshian, I. \& Sternberg, P.W. (1993). A free-living Panagrolaimus sp. from Armenia can survive in anhydrobiosis for 8.7 years. Journal of Nematology 25, 500502.

Barrière, A. \& Félix, M. (2006). Isolation of C. elegans and realted nematodes. In: The $C$. elegans Research Community (Eds). WormBook. Pasadena, CA, USA, pp. 1-9.

Benton, M.J., Donoghue, P.C.J. \& Asher, R.J. (2009). Calibrating and constraining molecular clocks. In: Hedges, S.B. \& Kumar, S. (Eds). The time tree of life. Oxford, UK, Oxford University Press, pp. 35-86.

Bladursson, S. \& Ingadóttir, A. (2007). Nomination of Surtsey for the UNESCO world heritage list. Reykjavík, Iceland, Icelandic Institute of Natural History.

Blaxter, M.L., De Ley, P., Garey, J.R., Liu, L.X., Scheldeman, P., Vierstraete, A., Vanfleteren, J.R., Mackey, L.Y., Dorris, M., Frisse, L.M. et al. (1998). A molecular evolutionary framework for the phylum Nematoda. Nature 392, 71-75. DOI: $10.1038 / 32160$

Bongers, T. (1990). The maturity index - an ecological measure of environmental disturbance based on nematode species composition. Oecologia 83, 14-19. DOI: 10.1007/ Bf00324627

Borgonie, G., Garcia-Moyano, A., Litthauer, D., Bert, W., Bester, A., van Heerden, E., Moller, C., Erasmus, M. \& Onstott, T.C. (2011). Nematoda from the terrestrial deep subsurface of South Africa. Nature 474, 79-82. DOI: 10.1038/ nature09974

Boström, S. (1988). Descriptions and morphological variability of three populations of Panagrolaimus Fuchs, 1930 (Nema- toda, Panagrolaimidae). Nematologica 34, 144-155. DOI: 10. 1163/002825988X00233

Brown, I.M., Wharton, D.A. \& Millar, R.B. (2004). The influence of temperature on the life history of the Antarctic nematode Panagrolaimus davidi. Nematology 6, 883-890. DOI: 10. 1163/1568541044038641

Caldwell, J.R. (1981). The Signy Island terrestrial reference sites: XIII. Population dynamics of the nematode fauna. British Antarctic Survey Bulletin 54, 33-46.

Clegg, J.S. (2001). Cryptobiosis - a peculiar state of biological organization. Comparative Biochemistry and Physiology Part B 128, 613-624. DOI: 10.1016/S1096-4959(01)00300-1

Cohen, K.M., Finney, S., Gibbard, P.L. \& Fan, J.-X. (2013; updated). International chronostratigraphic chart. Available online at http://www.stratigraphy.org/ICSchart/ ChronostratChart2017-02.pdf.

Convey, P. (2000). How does cold constrain life cycles of terrestrial plants and animals? CryoLetters 21, 73-82.

Convey, P. (2009). Comparative studies of Antarctic arthropod and bryophyte lifecycles: do they have a common strategy? In: Battaglia, B., Valencia, J. \& Walton, D.W.H. (Eds). Antarctic communities: species, structure and survival. Cambridge, UK, Cambridge University Press, pp. 321-327.

Convey, P. \& Stevens, M.I. (2007). Antarctic biodiversity. Science 317, 1877-1878. DOI: 10.1126/Science.1147261

Convey, P., Gibson, J.A.E., Hillenbrand, C.D., Hodgson, D.A., Pugh, P.J.A., Smellie, J.L. \& Stevens, M.I. (2008). Antarctic terrestrial life - challenging the history of the frozen continent? Biological Reviews 83, 103-117. DOI: 10.1111/J.1469185x.2008.00034.X

Coughlan, A. \& Wolfe, K.H. (2002). Fourfold faster rate of genome rearrangement in nematodes than in Drosophilia. Genome Research 12, 857-867. DOI: 10.1101/gr.172702

Crowe, J.H., Hoekstra, F.A. \& Crowe, L.M. (1992). Anhydrobiosis. Annual Review of Physiology 54, 579-599. DOI: 10. 1146/annurev.physiol.54.1.579

Cutter, A.D. (2008). Divergence times in Caenorhabditis and Drosophila inferred from direct estimates of the neutral mutation rate. Molecular Biology and Evolution 25, 778-786. DOI: 10.1093/Molbev/Msn024

Darby, B.J., Neher, D.A. \& Belnap, J. (2010). Impact of biological soil crusts and desert plants on soil microfaunal community composition. Plant and Soil 328, 421-431. DOI: 10.1007/s11104-009-0122-y

Drummond, A.J., Ho, S.Y.W., Phillips, M.J. \& Rambaut, A. (2006). Relaxed phylogenetics and dating with confidence. PLOS Biology 4, 699-710. DOI: 10.1371/Journal.Pbio. 0040088

Edgar, R.C. (2004). MUSCLE: multiple sequence alignment with high accuracy and high throughput. Nucleic Acids Research 32, 1792-1797. DOI: 10.1093/Nar/Gkh340

Erwin, D.H., Laflamme, M., Tweedt, S.M., Sperling, E.A., Pisani, D. \& Peterson, K.J. (2011). The Cambrian conundrum: early divergence and later ecological success in the 
early history of animals. Science 334, 1091-1097. DOI: 10. 1126/Science. 1206375

Flower, B.P. \& Kennett, J.P. (1993). Middle Miocene oceanclimate transition - high-resolution oxygen and carbon isotopic records from deep-sea drilling project site 588a, southwest Pacific. Paleoceanography 8, 811-843. DOI: 10.1029/ $93 \mathrm{pa} 02196$

Fonderie, P., Willems, M., Bert, W., Houthoofd, W., Steel, H., Claeys, M. \& Borgonie, G. (2009). Intestine ultrastructure of the facultative parasite Halicephalobus gingivalis (Nematoda: Panagrolaimidae). Nematology 11, 859-868. DOI: 10.1163/ 156854109X428025

Greenslade, P.J.M. (1983). Adversity selection and the habitat templet. American Naturalist 122, 352-365. DOI: 10.1086/ 284140

Ho, S.Y. \& Duchene, S. (2014). Molecular-clock methods for estimating evolutionary rates and timescales. Molecular Ecology 23, 5947-5965. DOI: 10.1111/mec.12953

Huang, X.Q. \& Madan, A. (1999). Cap3: a DNA sequence assembly program. Genome Research 9, 868-877. DOI: 10. 1101/Gr.9.9.868

Jia, F., Lo, N. \& Ho, S.Y. (2014). The impact of modelling rate heterogeneity among sites on phylogenetic estimates of intraspecific evolutionary rates and timescales. PLOS ONE 9, e95722. DOI: 10.1371/journal.pone.0095722

Kennett, J.P. (1977). Cenozoic evolution of Antarctic glaciation, the circum-Antarctic Ocean, and their impact on global paleocenography. Journal of Geophysical ResearchOceans and Atmospheres 82, 3843-3860. DOI: 10.1029/ JC082i027p03843

Lartillot, N. \& Philippe, H. (2004). A Bayesian mixture model for across-site heterogeneities in the amino-acid replacement process. Molecular Biology and Evolution 21, 1095-1109. DOI: 10.1093/Molbev/Msh112

Lartillot, N., Lepage, T. \& Blanquart, S. (2009). PhyloBayes 3: a Bayesian software package for phylogenetic reconstruction and molecular dating. Bioinformatics 25, 2286-2288. DOI: 10.1093/Bioinformatics/Btp368

Lazarova, S.S., de Goede, R.G.M., Peneva, V.K. \& Bongers, T. (2004). Spatial patterns of variation in the composition and structure of nematode communities in relation to different microhabitats: a case study of Quercus dalechampii Ten. forest. Soil Biology \& Biochemistry 36, 701-712. DOI: 10. 1016/j.soilbio.2004.01.005

Lepage, T., Bryant, D., Philippe, H. \& Lartillot, N. (2007). A general comparison of relaxed molecular clock models. Molecular Biology and Evolution 24, 2669-2680. DOI: 10. 1093/Molbev/Msm193

Lewis, S.C., Dyal, L.A., Hilburn, C.F., Weitz, S., Liau, W.S., LaMunyon, C.W. \& Denver, D.R. (2009). Molecular evolution in Panagrolaimus nematodes: origins of parthenogenesis, hermaphroditism and the Antarctic species P. davidi. BMC Evolutionary Biology 9, 15. DOI: 10.1186/1471-2148-9-15
Lynch, M. (2007). The origins of genome architecture. Sunderland, MA, USA, Sinauer Associates.

Maslen, N.R. \& Convey, P. (2006). Nematode diversity and distribution in the southern maritime Antarctic - clues to history? Soil Biology \& Biochemistry 38, 3141-3151. DOI: 10.1016/J.Soilbio.2005.12.007

McGill, L.M., Shannon, A.J., Pisani, D., Felix, M.A., Ramlov, H., Dix, I., Wharton, D.A. \& Burnell, A.M. (2015). Anhydrobiosis and freezing-tolerance: adaptations that facilitate the establishment of Panagrolaimus nematodes in polar habitats. PLOS ONE 10, e0116084. DOI: 10.1371/Journal.Pone. 0116084

Misof, B., Liu, S., Meusemann, K., Peters, R.S., Donath, A., Mayer, C., Frandsen, P.B., Ware, J., Flouri, T., Beutel, R.G. et al. (2014). Phylogenomics resolves the timing and pattern of insect evolution. Science 346, 763-767. DOI: 10.1126/ science. 1257570

Nicholas, W.L. (1984). The biology of free-living nematodes. Oxford, UK, Oxford University Press.

Nkem, J.N., Wall, D.H., Virginia, R.A., Barrett, J.E., Broos, E.J., Porazinska, D.L. \& Adams, B.J. (2006). Wind dispersal of soil invertebrates in the McMurdo Dry Valleys, Antarctica. Polar Biology 29, 346-352. DOI: 10.1007/S00300-0050061-X

Overhoff, A., Freckman, D.W. \& Virginia, R.A. (1993). Lifecycle of the microbivorous Antarctic dry valley nematode Scottnema lindsayae (Timm 1971). Polar Biology 13, 151156.

Poinar Jr, G.O. \& Boucot, A.J. (2006). Evidence of intestinal parasites of dinosaurs. Parasitology 133, 245-249. DOI: 10. 1017/S0031182006000138

Pugh, P.J.A. \& Convey, P. (2008). Surviving out in the cold: Antarctic endemic invertebrates and their refugia. Journal of Biogeography 35, 2176-2186. DOI: 10.1111/J.1365-2699. 2008.01953.X

Rota-Stabelli, O., Daley, A.C. \& Pisani, D. (2013). Molecular timetrees reveal a Cambrian colonization of land and a new scenario for ecdysozoan evolution. Current Biology 23, 392398. DOI: 10.1016/j.cub.2013.01.026

Schnyder, J., Dejax, J., Keppens, E., Tu, T.T.N., Spagna, P., Boulila, S., Galbrun, B., Riboulleau, A., Tshibangu, J.P. \& Yans, J. (2009). An Early Cretaceous lacustrine record: organic matter and organic carbon isotopes at Bernissart (Mons Basin, Belgium). Palaeogeography Palaeoclimatology Palaeoecology 281, 79-91. DOI: 10.1016/J.Palaeo.2009. 07.014

Shannon, A.J., Browne, J.A., Boyd, J., Fitzpatrick, D.A. \& Burnell, A.M. (2005). The anhydrobiotic potential and molecular phylogenetics of species and strains of Panagrolaimus $(\mathrm{Ne}-$ matoda, Panagrolaimidae). Journal of Experimental Biology 208, 2433-2445. DOI: 10.1242/jeb.01629

Stein, L.D., Bao, Z.R., Blasiar, D., Blumenthal, T., Brent, M.R., Chen, N.S., Chinwalla, A., Clarke, L., Clee, C., Coghlan, A. et al. (2003). The genome sequence of Caenorhabditis brig- 
gsae: a platform for comparative genomics. PLOS Biology 1, 166-192. DOI: 10.1371/Journal.Pbio.0000045

Stock, S.P. \& Nadler, S.A. (2006). Morphological and molecular characterisation of Panagrellus spp. (Cephalobina: Panagrolaimidae): taxonomic status and phylogenetic relationships. Nematology 8, 921-938. DOI: 10.1163/ 156854106779799277

Stocsits, R.R., Letsch, H., Hertel, J., Misof, B. \& Stadler, P.F. (2009). Accurate and efficient reconstruction of deep phylogenies from structured RNAs. Nucleic Acids Research 37, 6184-6193. DOI: 10.1093/Nar/Gkp600

Thorne, J.L., Kishino, H. \& Painter, I.S. (1998). Estimating the rate of evolution of the rate of molecular evolution. Molecular Biology and Evolution 15, 1647-1657.

Treonis, A.M., Wall, D.H. \& Virginia, R.A. (2000). The use of anhydrobiosis by soil nematodes in the Antarctic Dry Valleys. Functional Ecology 14, 460-467. DOI: 10.1046/J.1365-2435. 2000.00442.X

Vanfleteren, J.R., Van de Peer, Y., Blaxter, M.L., Tweedie, S.A., Trotman, C., Lu, L., Van Hauwaert, M.-L. \& Moens, L. (1994). Molecular genealogy of some nematode taxa as based on cytochrome c and globin amino acid sequences. Molecular Phylogenetics and Evolution 3, 92-101. DOI: 10.1006/mpev. 1994.1012

Welch, J.J. \& Bromham, L. (2005). Molecular dating when rates vary. Trends in Ecology \& Evolution 20, 320-327. DOI: 10. 1016/j.tree.2005.02.007

Wharton, D.A. \& Barclay, S. (1993). Anhydrobiosis in the freeliving antarctic nematode Panagrolaimus davidi (Nematoda: Rhabditida). Fundamental and Applied Nematology 16, 1722.
Wharton, D.A. \& Brown, I.M. (1989). A survey of terrestrial nematodes from the McMurdo Sound region, Antarctica. New Zealand Journal of Zoology 16, 467-470. DOI: 10.1080/ 03014223.1989.10422914

Wharton, D.A. \& Ferns, D.J. (1995). Survival of intracellular freezing by the Antarctic nematode Panagrolaimus davidi. Journal of Experimental Biology 198, 1381-1387.

Wharton, D.A. \& Raymond, M.R. (2015). Cold tolerance of the Antarctic nematodes Plectus murrayi and Scottnema lindsayae. Journal of Comparative Physiology B - Biochemical Systemic and Environmental Physiology 185, 281-289. DOI: 10.1007/s00360-014-0884-2

Wharton, D.A., Goodall, G. \& Marshall, C.J. (2002). Freezing rate affects the survival of a short-term freezing stress in Panagrolaimus davidi, an Antarctic nematode that survives intracellular freezing. CryoLetters 23, 5-10.

Yang, Z.H. \& Rannala, B. (2006). Bayesian estimation of species divergence times under a molecular clock using multiple fossil calibrations with soft bounds. Molecular Biology and Evolution 23, 212-226. DOI: 10.1093/molbev/msj024

Zhi, D.J., Li, H.Y. \& Nan, W.B. (2008). Nematode communities in the artificially vegetated belt with or without irrigation in the Tengger Desert, China. European Journal of Soil Biology 44, 238-246. DOI: 10.1016/j.ejsobi.2007.09.006

Zuckerkandl, E. \& Pauling, L.B. (1962). Molecular disease, evolution and genic heterogeneity. In: Kasha, M. \& Pullman, B. (Eds). Horizons in biochemistry: Albert Szent-Györgyi dedicatory volume. New York, NY, USA, Academic Press, pp. 97166. 


\section{Supplementary material}
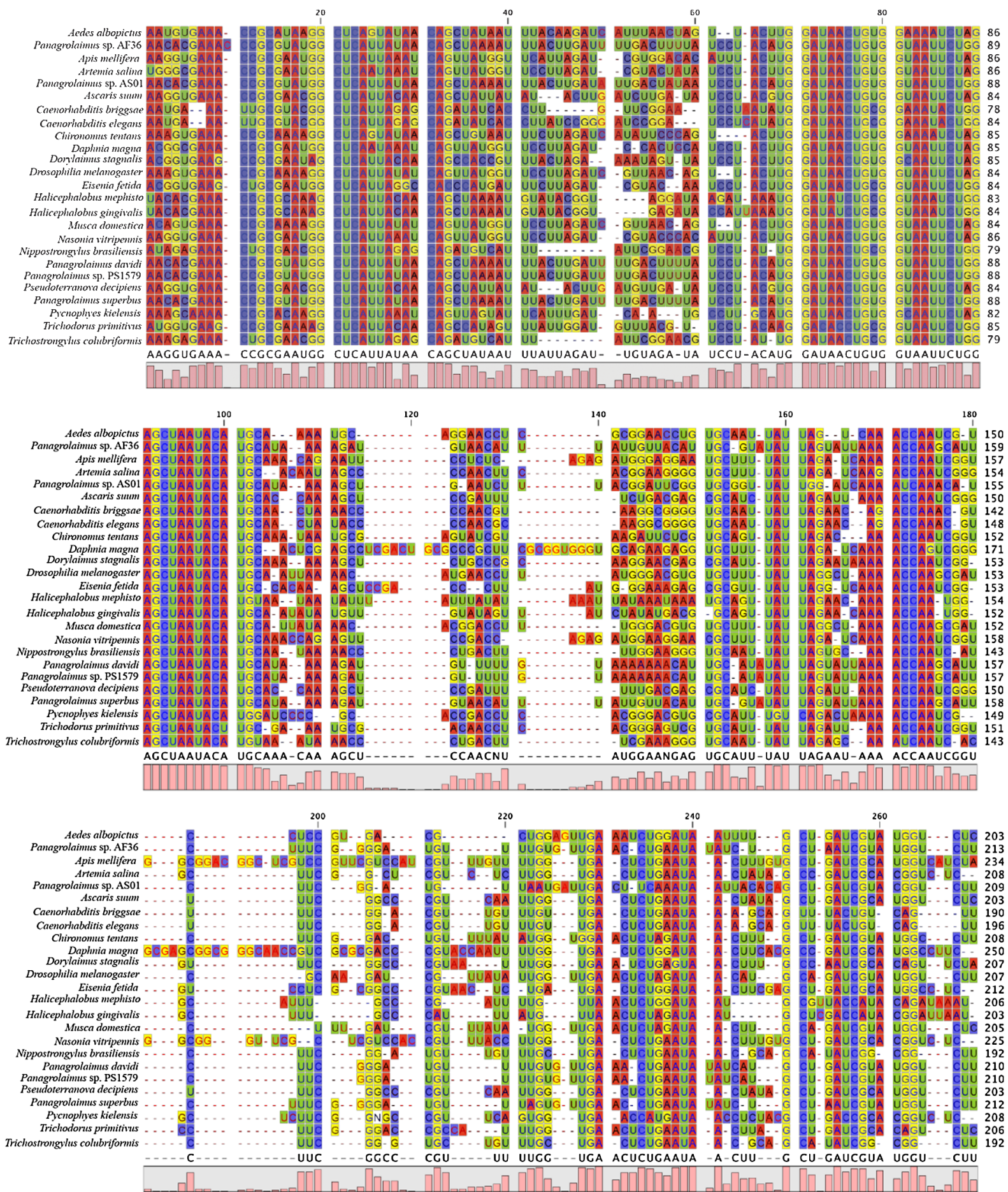

Fig. S1. Concatenated and trimmed 18S rDNA SSU and 28S rDNA D3 expansions region of LSU sequences generated using MUSCLE alignment software. 
300

320

340

360

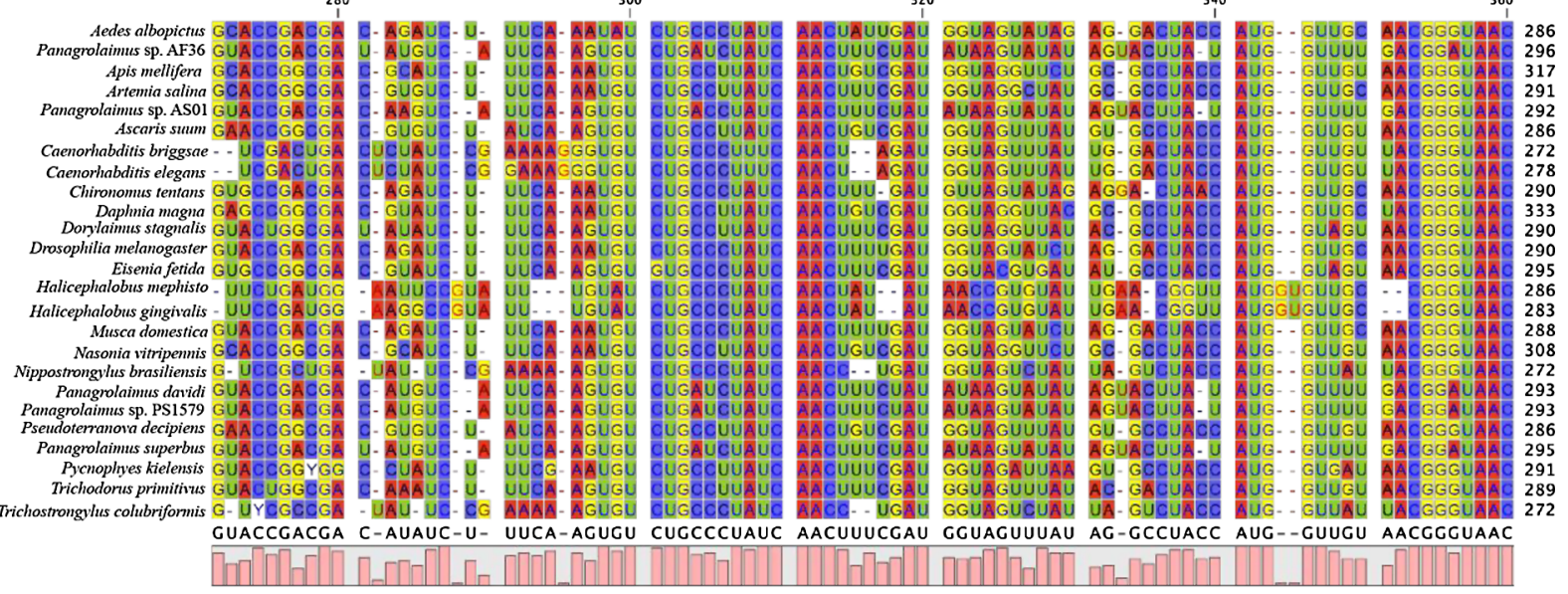

380
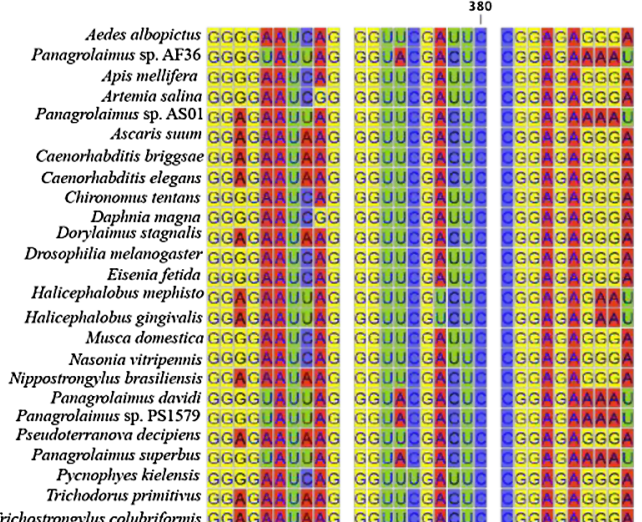

420

440

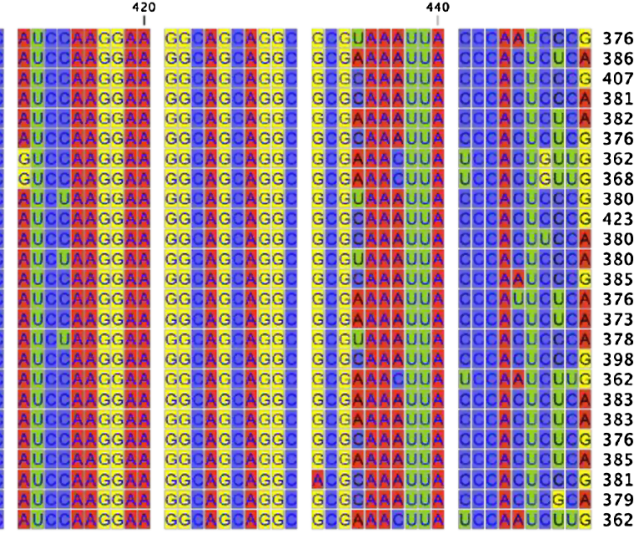

GGGGAAUCAG GGUUCGACUC CGGAGAGGGA GCCUGAGAAA CGGCUACCAC AUCCAAGGAA GGCAGCAGGC GCGAAAAUUA CCCACUCUCG

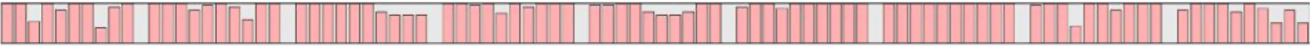

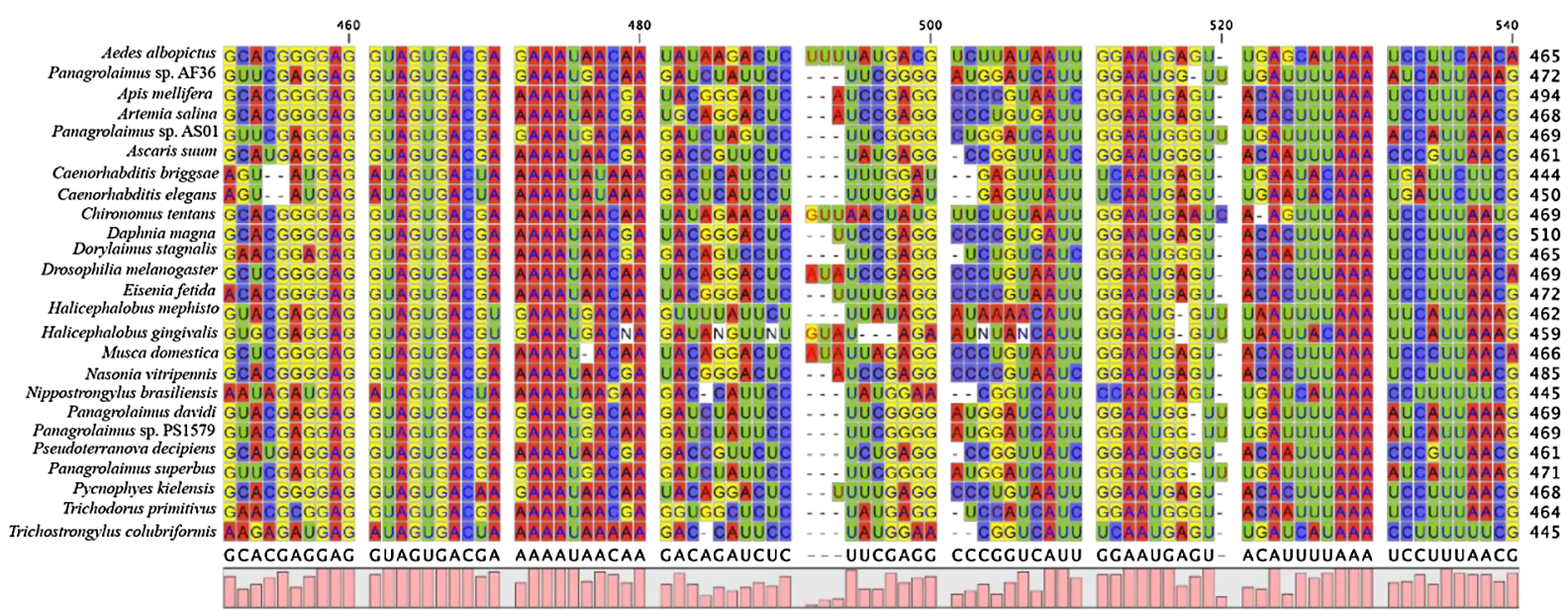

Fig. S1. (Continued.) 
620
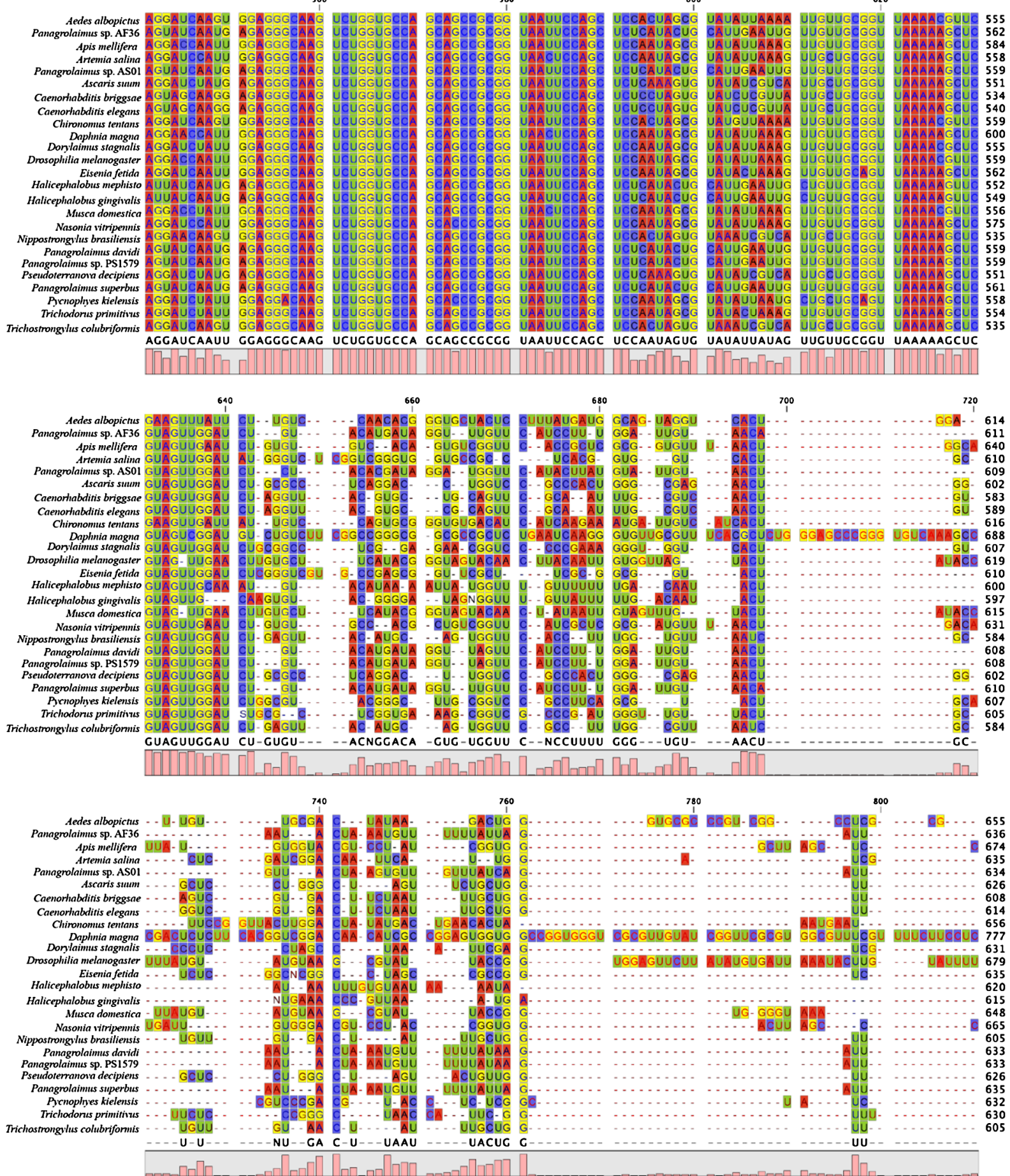

Fig. S1. (Continued.) 


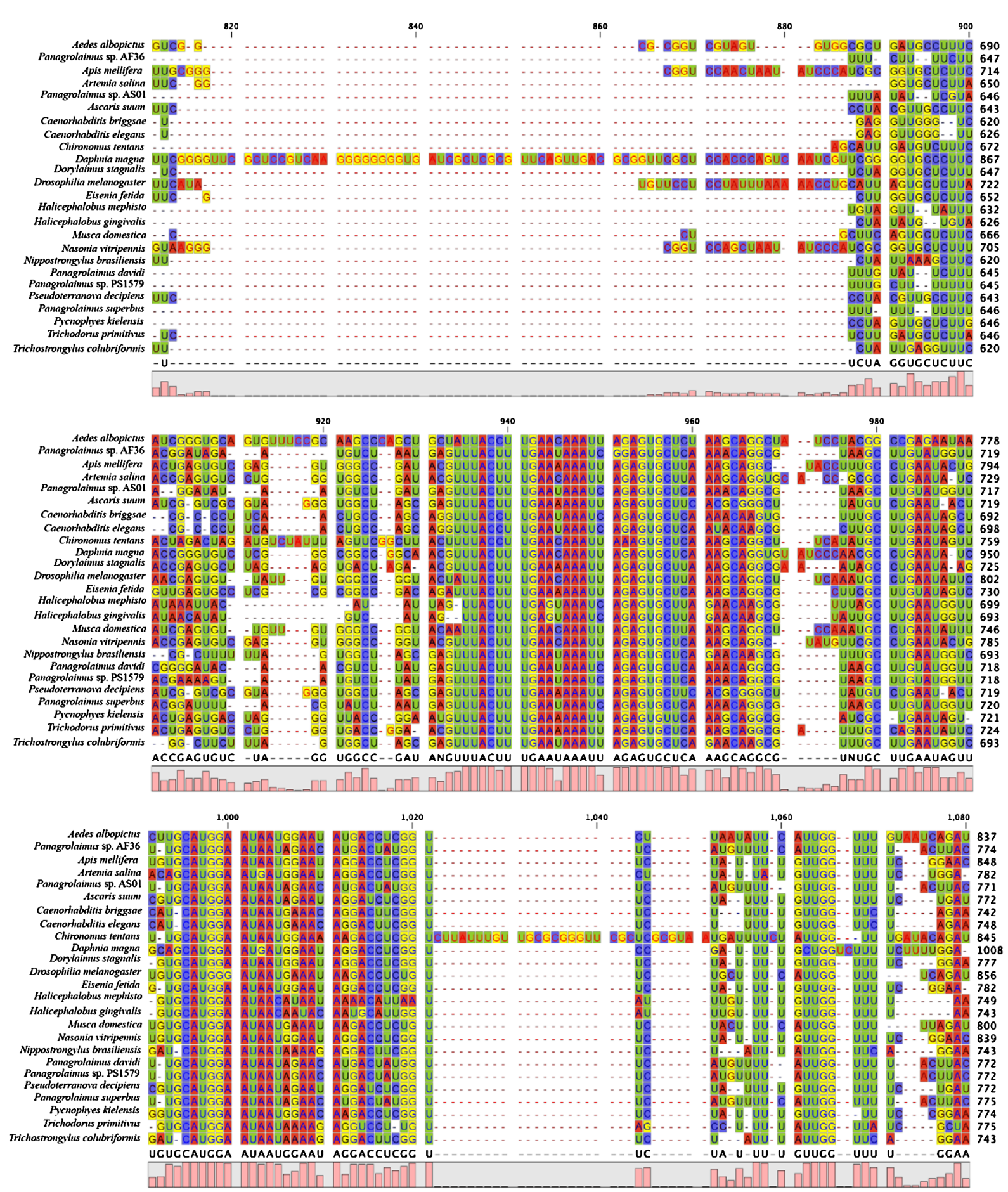

Fig. S1. (Continued.) 
1,100

1,120

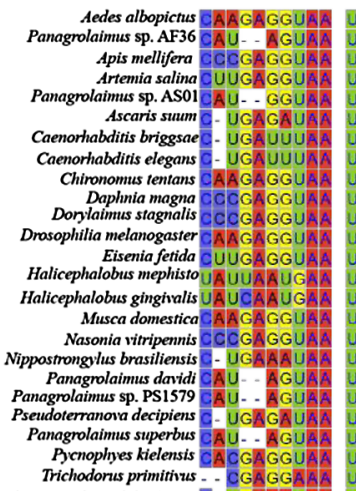

Trichastronglus colubritonis - CGAGGAAA UGAUCGAAGG UGAUAA UGGUUAAG

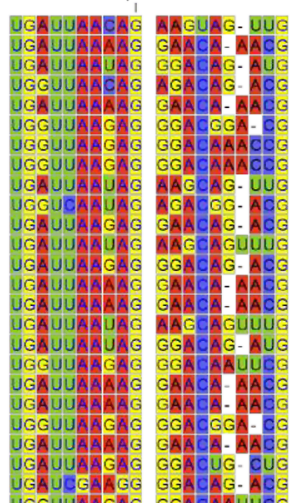

1,140

1,160

AAUUCGUAGA CCGUCGUAAG

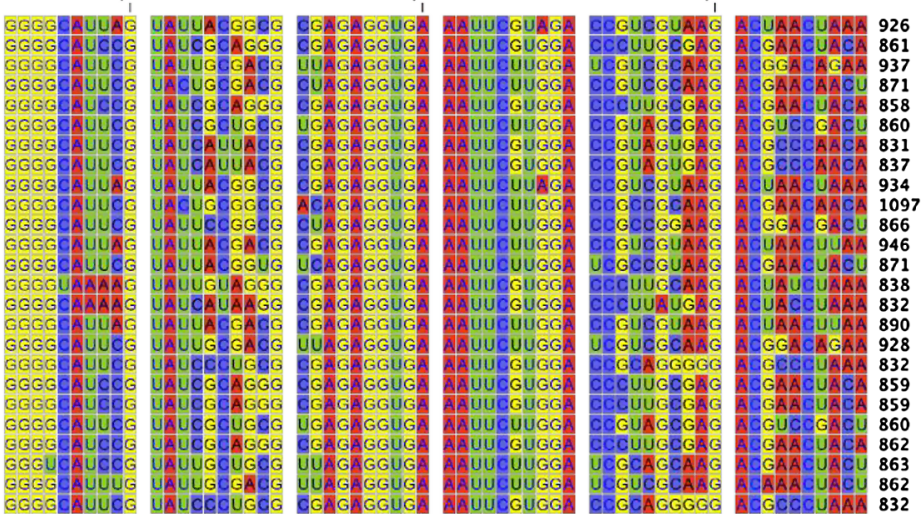
AAUUCUUGG UEGUCGCAAG ACAAACUACU $\mathbf{8 6 2}$

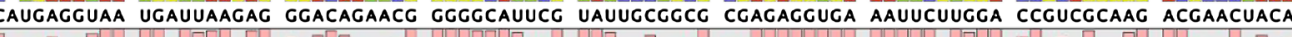
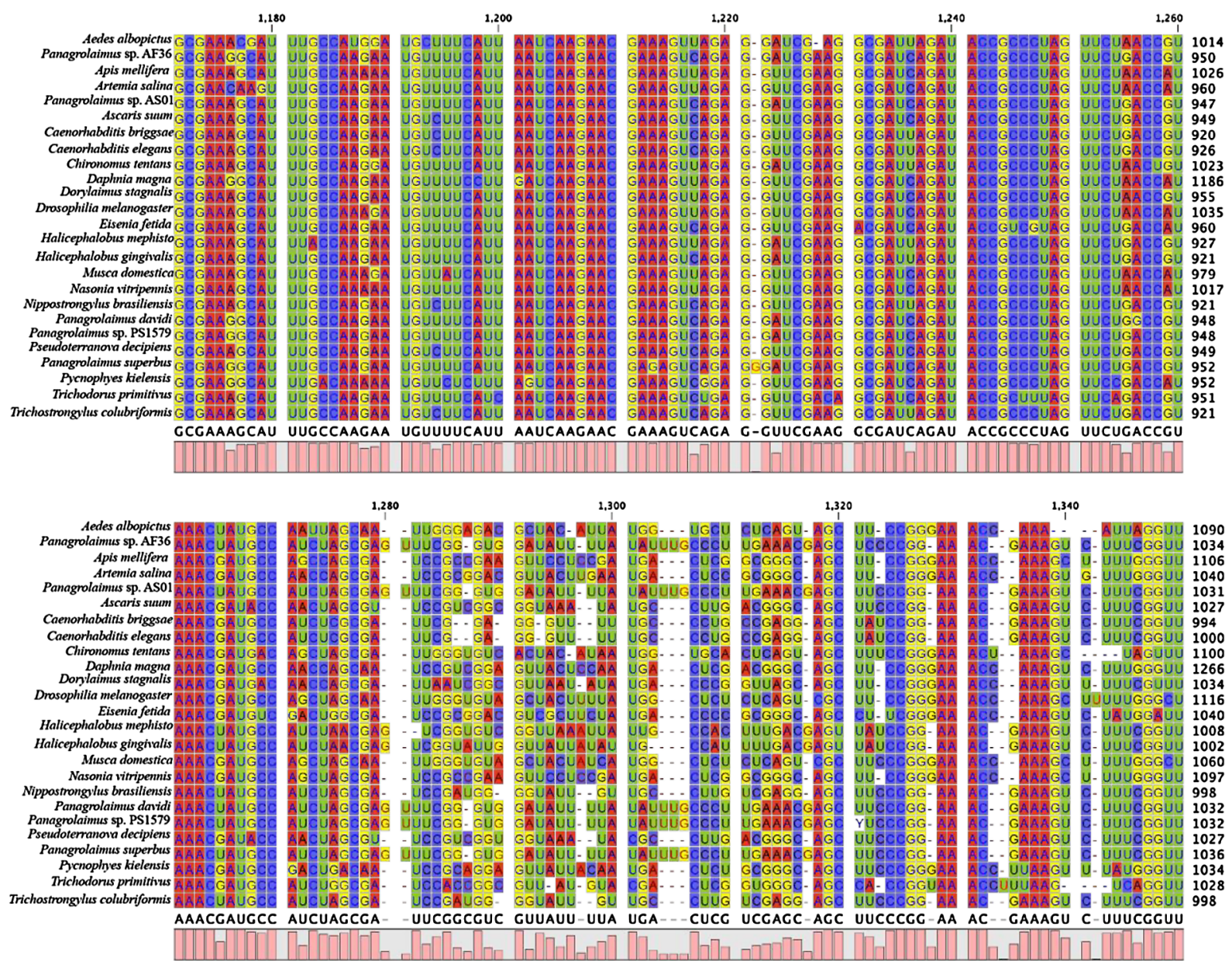

Fig. S1. (Continued.) 

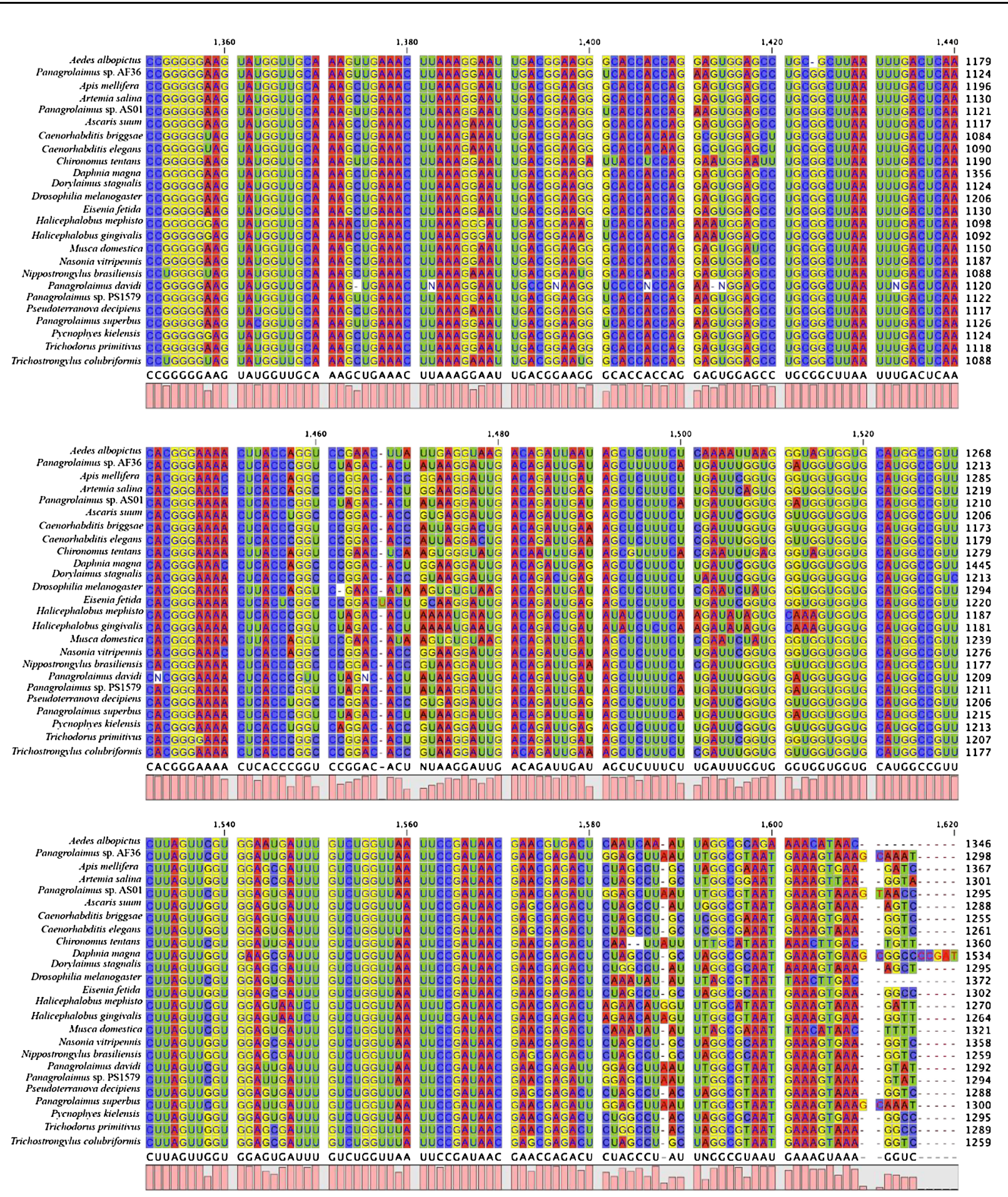

Fig. S1. (Continued.) 

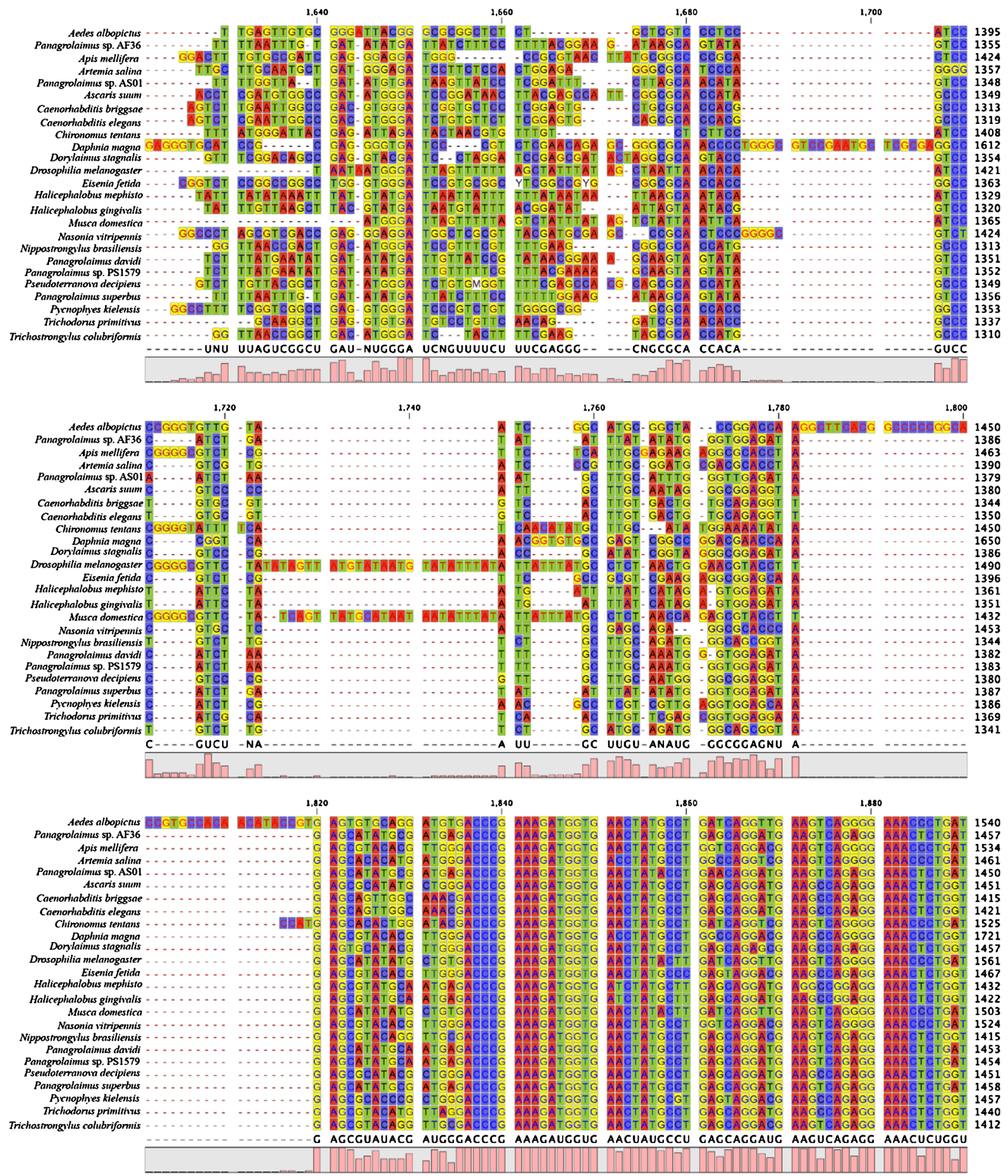

Fig. S1. (Continued.) 


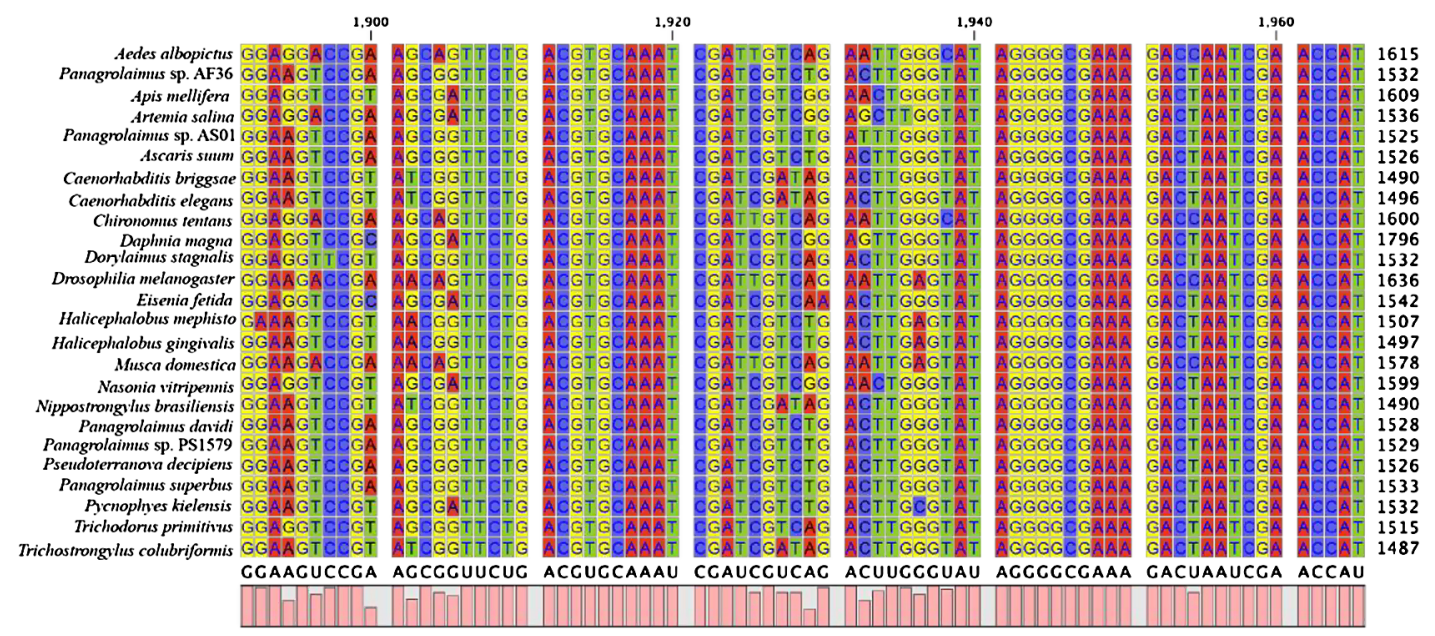

Fig. S1. (Continued.)

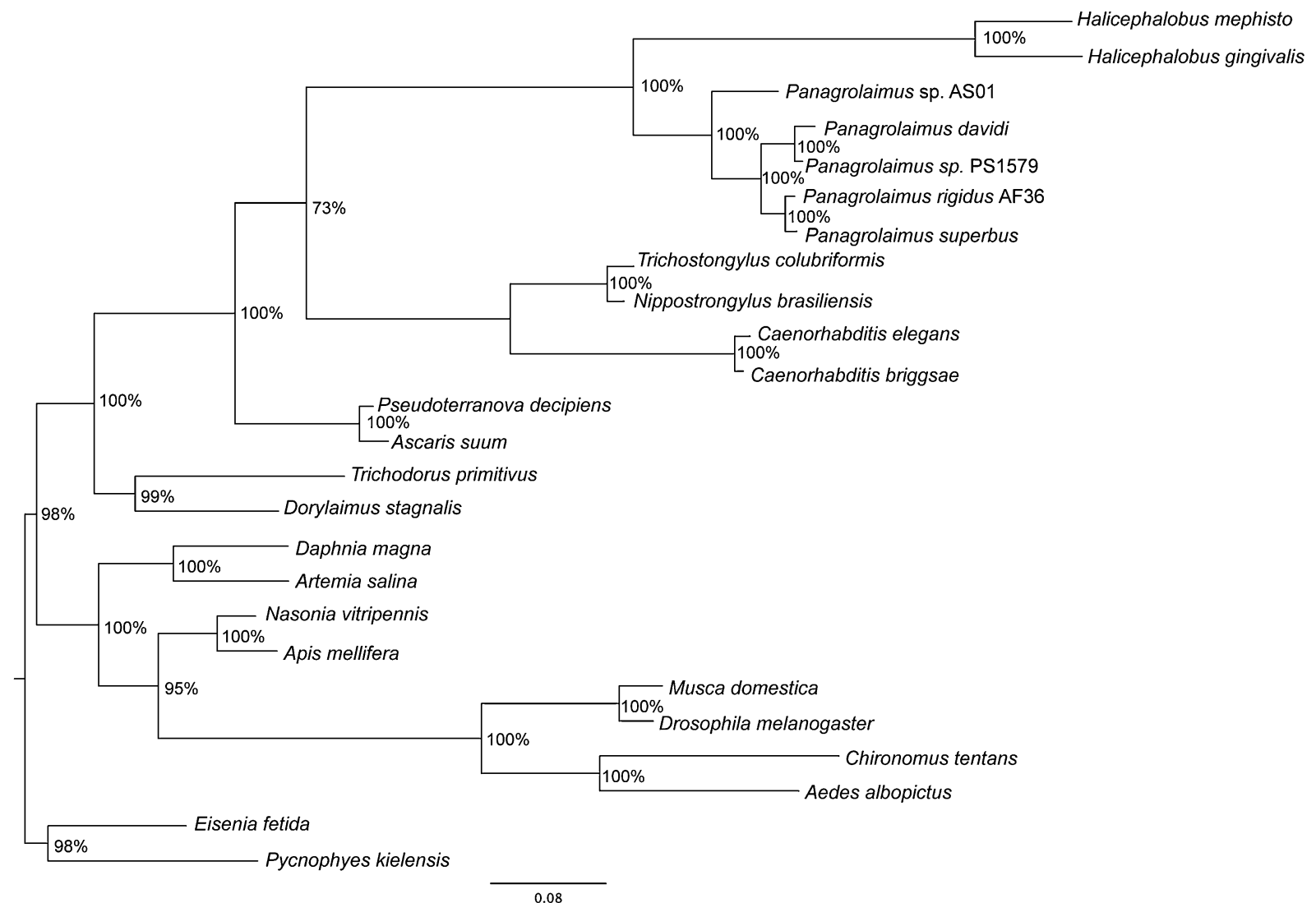

Fig. S2. Hypothesis of phylogenetic relationships among nematodes and arthropod species used for molecular clock analyses under the CAT nucleotide substitution model. Bayesian inference tree derived from concatenated sequences from the rDNA SSU and 28S rDNA D3 expansion regions of the LSU under the CAT nucleotide substitution model. The sequences were aligned using MUSCLE (Edgar, 2004) and the 18 S rDNA alignment was optimized with RNAsalsa (Stocsits et al., 2009). Branch supports are shown. 


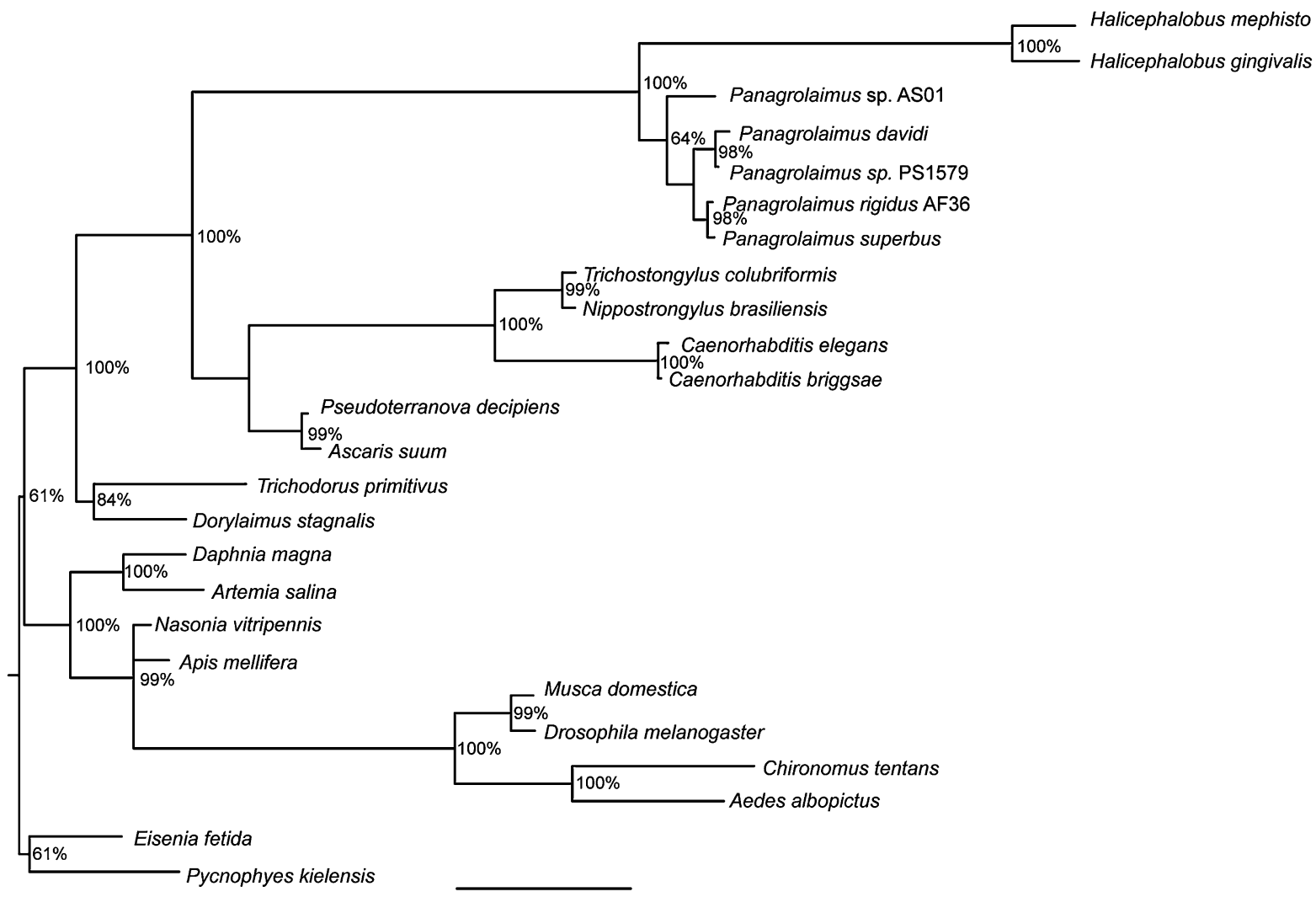

0.2

Fig. S3. Hypothesis of phylogenetic relationships among nematodes and arthropod species used for molecular clock analyses under the GTR nucleotide substitution model. Bayesian inference tree derived from concatenated sequences from the rDNA SSU and 28S rDNA D3 expansion regions of the LSU under the GTR nucleotide substitution model. The sequences were aligned using MUSCLE (Edgar, 2004) and the 18S rDNA alignment was optimized with RNAsalsa (Stocsits et al., 2009). Branch supports are shown. 


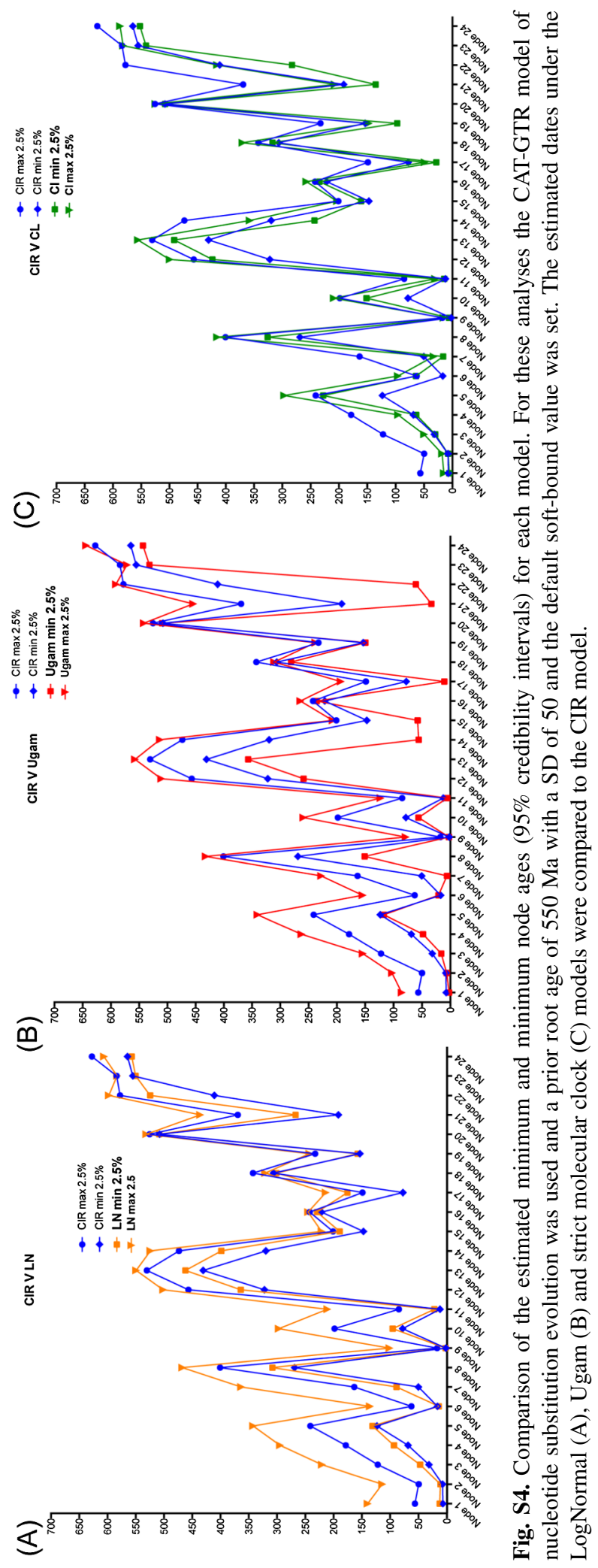

Vol. 19(8), 2017 
เ $\left(\begin{array}{llllll}0 & 0 & 0 & 0 & 0 & 0\end{array}\right.$

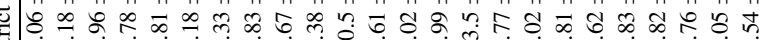
की

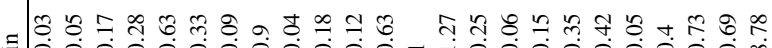

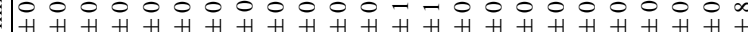

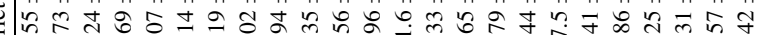

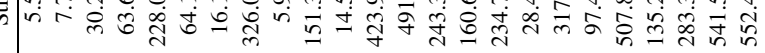

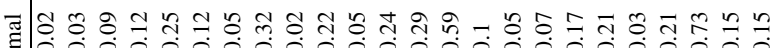

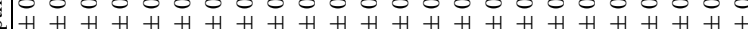
ㄷำ

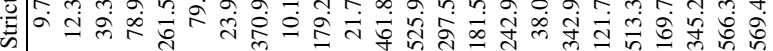

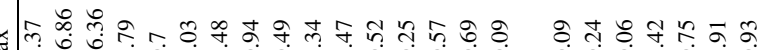
H

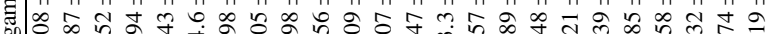

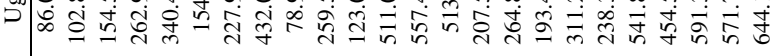

ప

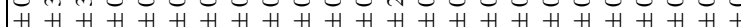

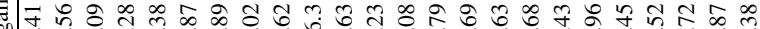
$\supset$ i

चّ 年 $H+H+H+H+H+H+H+H+H+H+H+H+H+H+H+H+1$

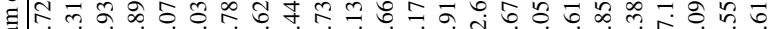
类

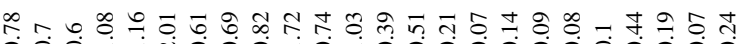

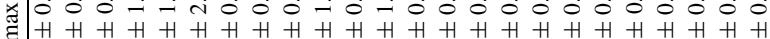

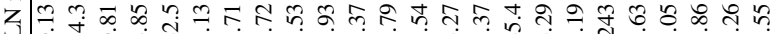

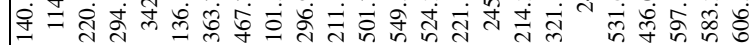

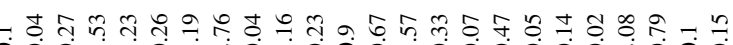
然

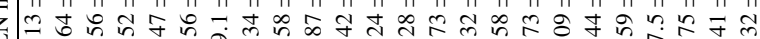
=

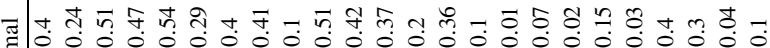
H H H H H H H H H H H H H H H H H H H H H H H H

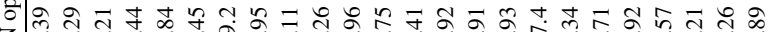

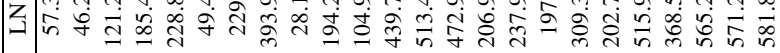

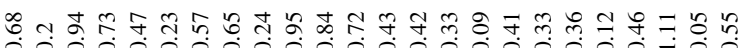

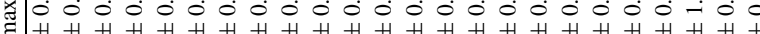

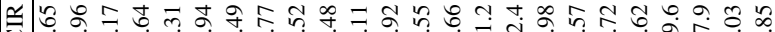

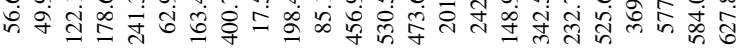

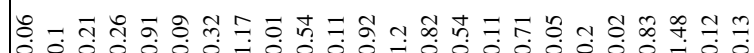

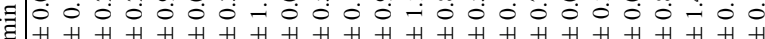

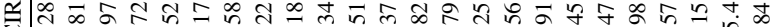

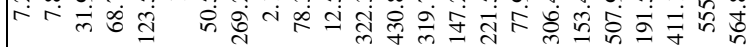

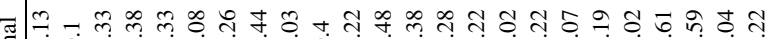
-

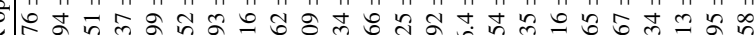

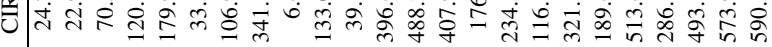




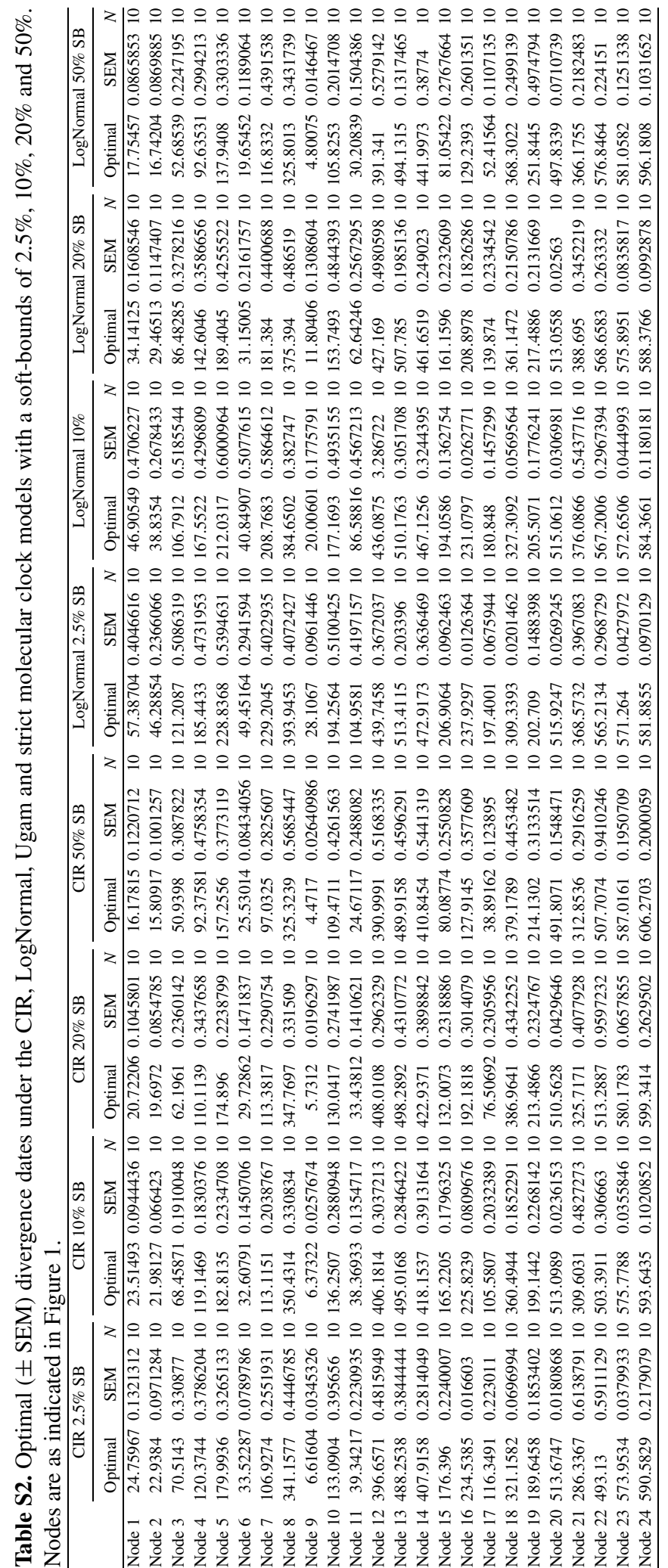




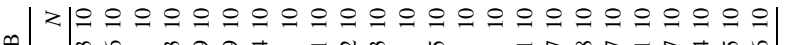

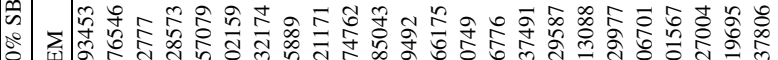

品

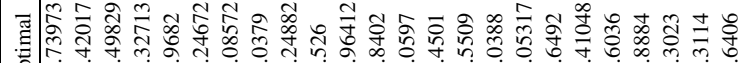

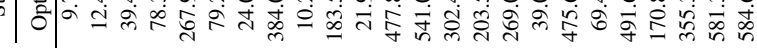

| $z$ 으으으으으으으으으으으으으으으으으으으으으으으

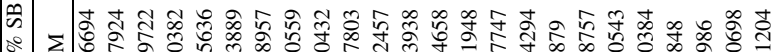

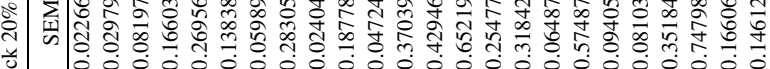

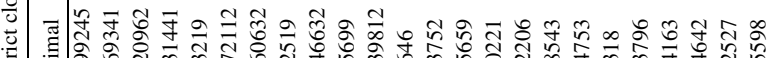

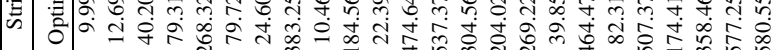

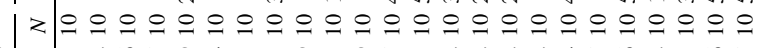

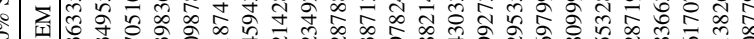

青

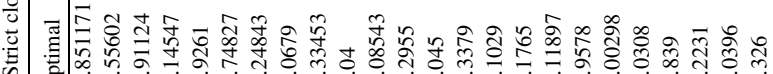

至

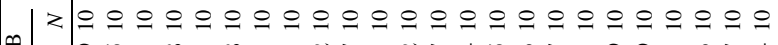

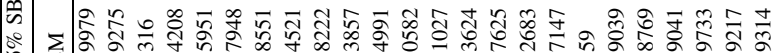

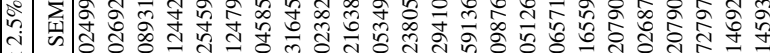

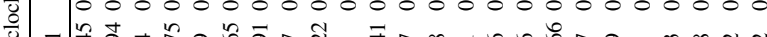

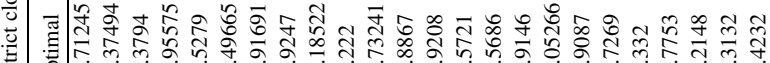

क oे बं

z 으으으으으으으으으으으으으으으으으으으으으으으

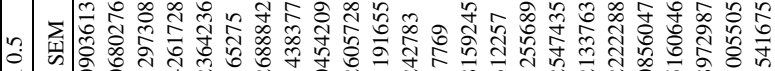

击

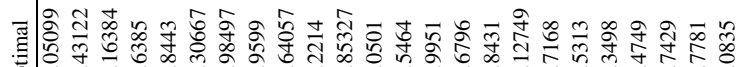

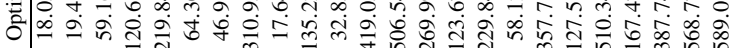

$z$ 으으으으으으으으으으으으으으으으으으으

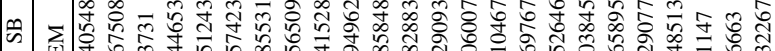

党

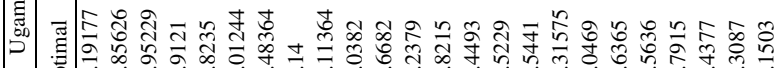
के ते ते

z 으으으으으으으으으으으으으으으으으으으으으으으

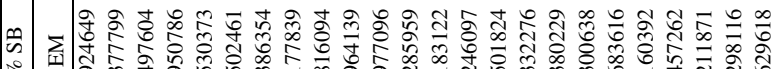

罚

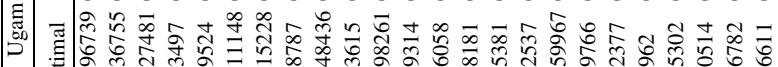

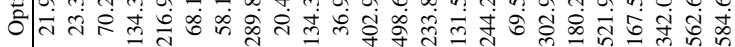

$z$ z으으응ㅇㅇㅇㅇ으응ㅇㅇㅇㅇㅇㅇㅇㅇㅇㅇㅇㅇㅇㅇㅇㅇㅇㅡ

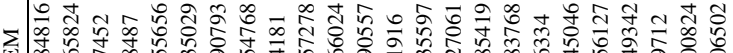

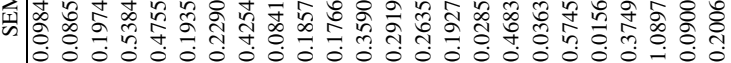

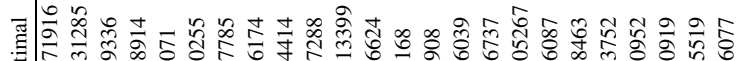

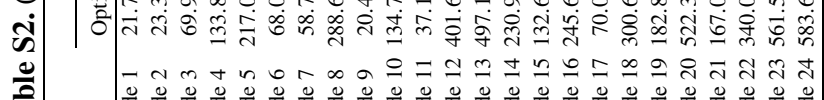

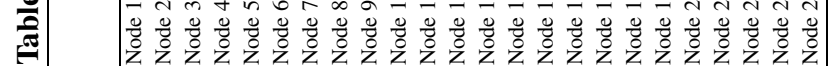




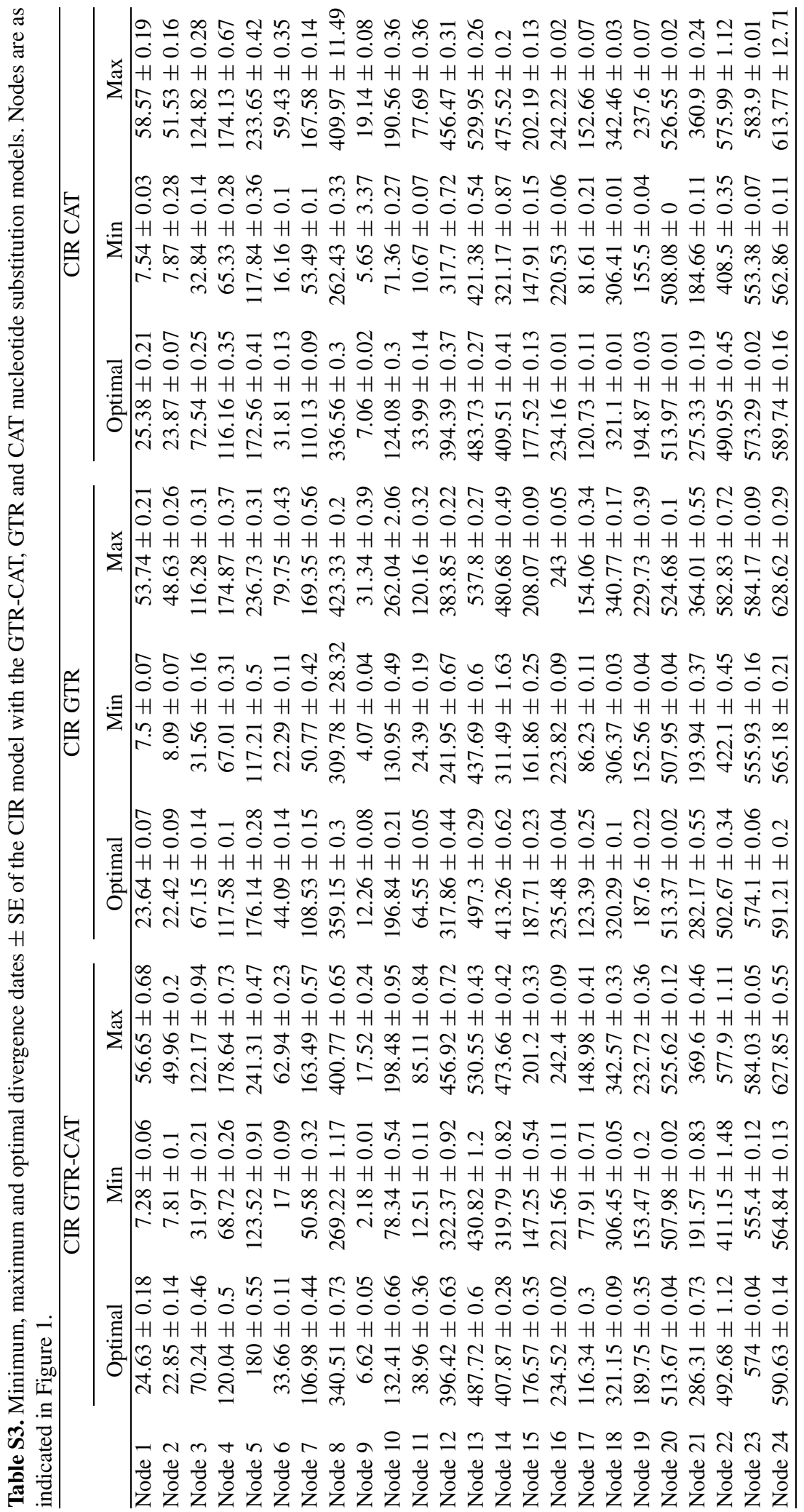


Table S4. Optimal divergence dates \pm SEM of the CIR model with a soft-bound of $2.5 \%$ and a SD of 50 and 20. Nodes are as indicated in Figure 1.

\begin{tabular}{|c|c|c|c|c|c|c|}
\hline & \multicolumn{3}{|c|}{ CIR $2.5 \%$ SD 50} & \multicolumn{3}{|c|}{ CIR $2.5 \%$ SD 20} \\
\hline & Optimal & SEM & $N$ & Optimal & SEM & $N$ \\
\hline Node 1 & 24.75967 & 0.1321312 & 10 & 24.72956 & 0.1550461 & 5 \\
\hline Node 2 & 22.9384 & 0.0971284 & 10 & 22.85796 & 0.0898685 & 5 \\
\hline Node 3 & 70.5143 & 0.330877 & 10 & 70.25706 & 0.3607412 & 5 \\
\hline Node 4 & 120.3744 & 0.3786204 & 10 & 120.3562 & 0.4740049 & 5 \\
\hline Node 5 & 179.9936 & 0.3265133 & 10 & 179.9369 & 0.4681844 & 5 \\
\hline Node 6 & 33.52287 & 0.0789786 & 10 & 33.59406 & 0.1303464 & 5 \\
\hline Node 7 & 106.9274 & 0.2551931 & 10 & 106.2985 & 0.1627454 & 5 \\
\hline Node 8 & 341.1577 & 0.4446785 & 10 & 339.7329 & 0.4945394 & 5 \\
\hline Node 9 & 6.61604 & 0.0345326 & 10 & 6.66732 & 0.0298782 & 5 \\
\hline Node 10 & 133.0904 & 0.395656 & 10 & 132.7643 & 0.4853723 & 5 \\
\hline Node 11 & 39.34217 & 0.2230935 & 10 & 39.43874 & 0.170724 & 5 \\
\hline Node 12 & 396.6571 & 0.4815949 & 10 & 395.3095 & 0.4893206 & 5 \\
\hline Node 13 & 488.2538 & 0.3844444 & 10 & 486.2714 & 0.4770738 & 5 \\
\hline Node 14 & 407.9158 & 0.2814049 & 10 & 406.1426 & 0.2275182 & 5 \\
\hline Node 15 & 176.396 & 0.2240007 & 10 & 176.9531 & 0.1891135 & 5 \\
\hline Node 16 & 234.5385 & 0.016603 & 10 & 234.5495 & 0.0260538 & 5 \\
\hline Node 17 & 116.3491 & 0.223011 & 10 & 116.6393 & 0.3407698 & 5 \\
\hline Node 18 & 321.1582 & 0.0696994 & 10 & 320.8926 & 0.1477149 & 5 \\
\hline Node 19 & 189.6458 & 0.1853402 & 10 & 188.9605 & 0.1164389 & 5 \\
\hline Node 20 & 513.6747 & 0.0180868 & 10 & 513.5178 & 0.0239012 & 5 \\
\hline Node 21 & 286.3367 & 0.6138791 & 10 & 286.7066 & 0.6535592 & 5 \\
\hline Node 22 & 493.13 & 0.5911129 & 10 & 487.2673 & 0.7695808 & 5 \\
\hline Node 23 & 573.9534 & 0.0379933 & 10 & 571.1469 & 0.0449154 & 5 \\
\hline Node 24 & 590.5829 & 0.2179079 & 10 & 580.62 & 0.0879979 & 5 \\
\hline
\end{tabular}

